\title{
Cancer cell specific inhibition of Wnt/ $\beta$-catenin signaling by forced intracellular acidification
}

Svitlana Melnik ${ }^{1,2}$, Dmytro Dvornikov ${ }^{3,4}$, Karin Müller-Decker ${ }^{5}$, Sofia Depner ${ }^{3}$, Peter Stannek ${ }^{6}$, Michael Meister ${ }^{4,7}$, Arne Warth ${ }^{4,8}$, Michael Thomas ${ }^{4,7}$, Tomas Muley ${ }^{4,7}$, Angela Risch ${ }^{1,4,9,10}$, Christoph Plass (D) ${ }^{1,4}$, Ursula Klingmüller ${ }^{3,4}$, Christof Niehrs ${ }^{6,11}$ and Andrey Glinka ${ }^{6}$

\begin{abstract}
Use of the diabetes type II drug Metformin is associated with a moderately lowered risk of cancer incidence in numerous tumor entities. Studying the molecular changes associated with the tumor-suppressive action of Metformin we found that the oncogene SOX4, which is upregulated in solid tumors and associated with poor prognosis, was induced by Wnt/ $\beta$-catenin signaling and blocked by Metformin. Wnt signaling inhibition by Metformin was surprisingly specific for cancer cells. Unraveling the underlying specificity, we identified Metformin and other Mitochondrial Complex I (MCI) inhibitors as inducers of intracellular acidification in cancer cells. We demonstrated that acidification triggers the unfolded protein response to induce the global transcriptional repressor DDIT3, known to block Wnt signaling. Moreover, our results suggest that intracellular acidification universally inhibits Wnt signaling. Based on these findings, we combined $\mathrm{MCl}$ inhibitors with $\mathrm{H}^{+}$ionophores, to escalate cancer cells into intracellular hyper-acidification and ATP depletion. This treatment lowered intracellular pH both in vitro and in a mouse xenograft tumor model, depleted cellular ATP, blocked Wnt signaling, downregulated SOX4, and strongly decreased stemness and viability of cancer cells. Importantly, the inhibition of Wnt signaling occurred downstream of $\beta$-catenin, encouraging applications in treatment of cancers caused by APC and $\beta$-catenin mutations.
\end{abstract}

\section{Introduction}

Epidemiological studies have established that regular use of Metformin lowers the incidence risk for many cancer entities, including colorectal adenocarcinoma ${ }^{1}$. Also, Metformin has been shown to cooperate in elimination of cancer cells in combination with a number of other $\operatorname{drugs}^{2,3}$, as well as with radiotherapy ${ }^{4,5}$. Metformin represents a universal, but very weak, anticancer drug. Metaanalyses of multiple studies support its antitumor effect, affecting, for example, cancers of lung ${ }^{6}$, prostate ${ }^{7}$, and

Correspondence: Andrey Glinka (glinka@dkfz.de)

${ }^{1}$ Division of Epigenetics and Cancer Risks Factors, German Cancer Research Center, Heidelberg D-69120, Germany

²NA vectors, German Cancer Research Center, Heidelberg D-69120, Germany Full list of author information is available at the end of the article.

These authors contributed equally: Svitlana Melnik, Dmytro Dvornikov. endometrium ${ }^{8}$. However, in some studies no improvement was observed, e.g., with non-small cell lung cancer $(\mathrm{NSCLC})^{9}$.

The mechanism for Metformin's anti-cancer specificity remains unclear. It has been proposed that the antidiabetic property of Metformin might also account for its anticancer effect. While previous studies have suggested that activation of AMPK (AMP-activated protein kinase) mediates the anticancer action of Metformin ${ }^{10,11}$, this has remained controversial ${ }^{12,13}$. In addition, Metformin can inhibit mitochondrial GPD2 (Glycerol-3-Phosphate Dehydrogenase 2$)^{14}$. A characteristic feature of Metformin and other biguanidine-type drugs is their ability to reduce cellular ATP level by inhibition of mitochondrial complex I (MCI) accompanied by compensatory increase rate of glycolysis in sensitive cells ${ }^{15}$. In general, MCI

\section{(c) The Author(s) 2018}

(c) (i) Open Access This article is licensed under a Creative Commons Attribution 4.0 International License, which permits use, sharing, adaptation, distribution and reproduction c. in any medium or format, as long as you give appropriate credit to the original author(s) and the source, provide a link to the Creative Commons license, and indicate if changes were made. The images or other third party material in this article are included in the article's Creative Commons license, unless indicated otherwise in a credit line to the material. If material is not included in the article's Creative Commons license and your intended use is not permitted by statutory regulation or exceeds the permitted use, you will need to obtain permission directly from the copyright holder. To view a copy of this license, visit http://creativecommons.org/licenses/by/4.0/. 
inhibitors are known for their anticancer properties ${ }^{16-18}$. A moderate inhibition of MCI with therapeutical doses of MCI inhibitors causes no side effects in routine medical practice (Metformin, Phenformin, and Papaverine). However, a disadvantage of Metformin as an anticancer drug is a necessity to apply it at very high concentrations in in vitro experiments to achieve substantial effects. To reach similar outcome in cancer patients, the drug has to be applied at doses that might trigger lactic acidosis as a side-effect. Insights into Metformin's anticancer mechanism could help to suggest more effective drugs with similar but enhanced properties.

Since Metformin affects tumor cells from multiple tissue entities, this suggests that there are some underlying common molecular markers. Evaluation of these markers would help monitoring molecular changes caused by Metformin. The most pronounced anticancer effects for Metformin have been reported for colorectal adenocarcinoma cases ${ }^{1}$. It is well-established that in many instances colorectal cancer is caused by aberrant Wnt signaling ${ }^{19,20}$. At the same time, SOX4 (SRY (Sex Determining Region Y)-box 4), a transcription factor and oncogene expressed in many types of tumors ${ }^{21,22}$, has been found to be a prognostic marker of poor outcome for colon cancer patients ${ }^{23}$. These observations point to a probable link between Metformin, Wnt signaling and SOX4. High expression levels of SOX4 correlate with cancer patients mortality rates, regardless of other clinical parameters ${ }^{21}$. Conversely, it has been demonstrated that knockdown of the SOX4 gene in xenograft model suppresses tumor growth ${ }^{24}$. Normal SOX4 expression is limited to embryonic cells and some adult tissues such as pancreas, intestine, and skin. It is also expressed in a number of human non-cancer cell lines of embryonic origin ${ }^{25}$. SOX4 expression is linked to cell migration, proliferation, Epithelial-toMesenchymal transition (EMT) and metastasis formation $^{26}$. Thus, SOX4 would be a candidate for a universal oncogene that is independent of a tumor entity, and at the same time is expressed in non-cancer cells of embryonic origin. These two important features could be used to assess both specificity and efficiency of tested cancer-suppressing treatments.

Upregulation of Wnt signaling is a strong cancerdriving force for multiple types of malignancies ${ }^{19}$, and in particular, is a primary cause of colon cancer ${ }^{20}$. Predominant reasons for such Wnt signaling upregulation are loss-of-function mutations for $A P C$, which promotes $\beta$-catenin degradation. As a result, $\beta$-catenin protein accumulates and, upon binding LEF/TCF transcription factors and co-activators of transcription $\mathrm{CBP} / \mathrm{p} 300$, forms an 'activator complex'. This complex binds to LEF/ TCF binding sites at promoters of Wnt target genes. Abnormal accumulation of $\beta$-catenin therefore causes overexpression of specific Wnt target genes, including AXIN2, and a number of potential oncogenes ${ }^{27}$. In addition, a variety of stabilizing mutations in $\beta$-catenin gene cause similar effects as $A P C$ mutations. $\beta$-catenin and $A P C$ mutations account for $95 \%$ incidences of colorectal cancer. Mutations resulting in $\beta$-catenin accumulation are not limited to colon cancer, and often found in tumors of other origin: liver (hepatocellular carcinoma ${ }^{28}$ ), kidney ${ }^{29}$, ovary $^{30}$, prostate ${ }^{31}$, brain (medulloblastoma ${ }^{32}$ ), endometrial cancer ${ }^{33}$ and thyroid gland ${ }^{34}$. In addition, Wnt signaling is a major positive contributor in multiple cancer stem cells functions ${ }^{27,35}$ and also is a driving force of lung adenocarcinoma ${ }^{36}$.

Multiple attempts have been made to develop drugs inhibiting Wnt signaling (reviewed by Novellasdemunt et al. $\left.{ }^{20}\right)$. Only a few of the found drugs could target $\beta$-catenin/TCF interactions, to block Wnt signaling at the level of $\beta$-catenin ${ }^{37}$. A main pitfall of these drugs, however, is the absence of specificity towards cancer cells, and accompanying side effects.

In this study, we addressed the mechanism of the universal anticancer properties of Metformin and discovered its ability to block Wnt signaling specifically in cancer cells. We applied these findings to develop a new cancer cell specific strategy for Wnt/ $\beta$-catenin signaling inhibition that exploits a characteristic feature of cancer cell metabolism, - the Warburg effect ${ }^{38}$. We found that this strategy resulted in consequent cancer cells elimination without causing any significant effects in non-cancer cells.

\section{Results}

\section{Metformin inhibits Wnt/ $\beta$-catenin signaling}

Wnt signaling can be induced in cultured cells by applying Wnt3a protein and monitored either by measuring $\beta$-catenin protein stabilization or induction of its immediate downstream target gene AXIN2. We found that Metformin inhibits Wnt signaling as monitored by AXIN2 expression, but only moderately affects levels of $\beta$ catenin protein accumulation (Fig. 1a). Moreover, we found that the expression of an oncogene SOX4, which we identified to be Wnt3a-inducible, and with similar kinetics of mRNA and protein levels induction to the Wnt target gene AXIN2 (Supplementary Fig. S1a-b), was also inhibited by Metformin (Fig. 1a-c). Treatment with siß-catenin RNA prevented SOX4 induction upon Wnt3a treatment, and conversely, SOX4 was induced by $\beta$-catenin overexpression (Supplementary Fig. S1c-d). However, in cancer cell lines DLD1, HCT116, and H1975, siß-catenin did not affect SOX4 expression (Supplementary Fig. S1e), indicating that SOX4 expression does not universally require Wnt signaling. Yet, in these cell lines, Metformin still blocked SOX4 (Fig. 1b-c), suggesting that Metformin can affect SOX4 expression also independently of Wnt signaling. Interestingly, Metformin had no inhibiting 


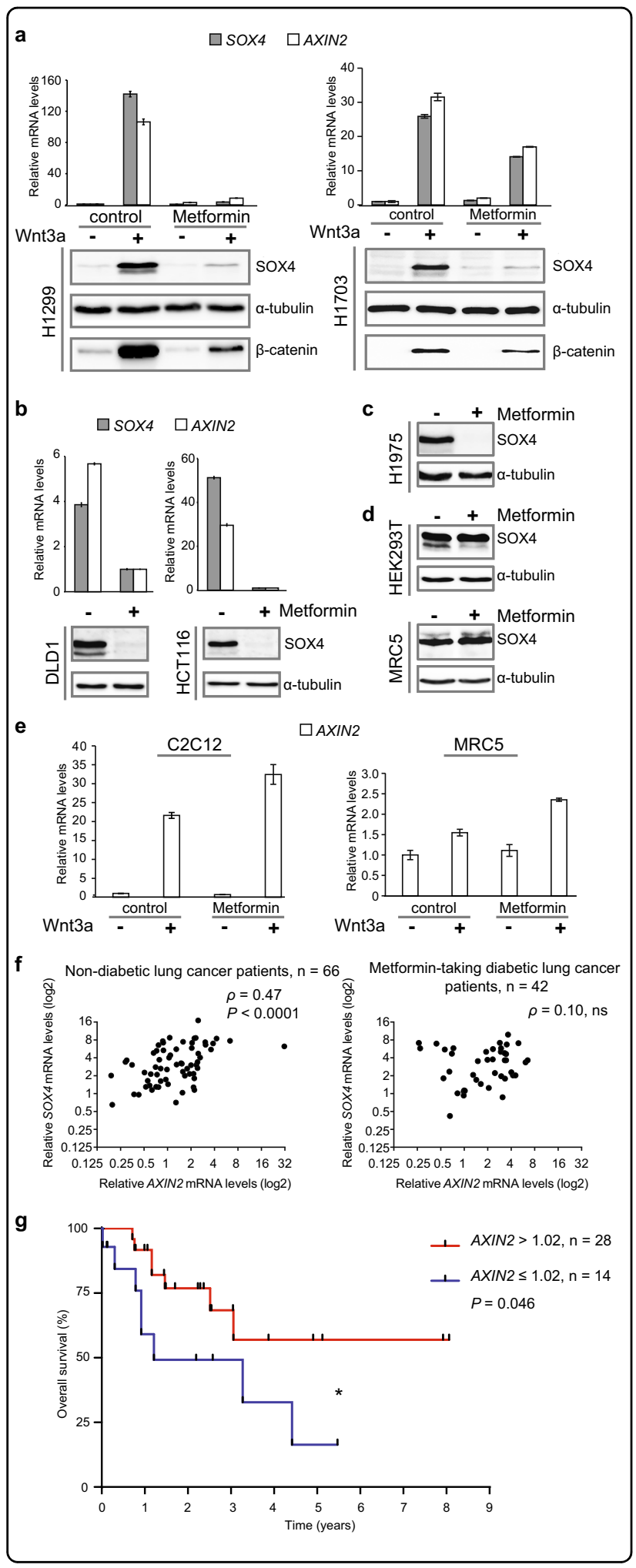

effect on SOX4 and AXIN2 levels in non-cancer cell lines (HEK293T, MRC5, and C2C12, Fig. 1d-e). We conclude that expression of SOX4 is Wnt-inducible and sensitive to Metformin preferentially in cancer cells.
Fig. 1 Metformin inhibits Wnt signaling. a-e Levels of the indicated mRNAs and proteins were monitored in the indicated cell lines by qRT-PCR or WB, respectively. Error bars represent mean values $\pm S D$. $\mathbf{f}$ Non-linear Spearman's rank correlation analysis of SOX4 mRNA expression levels with Wnt signaling (AXIN2) in tumor tissue samples from lung cancer patients, non-diabetic or Metformin-taking diabetic. $\rho$ Spearman's rank coefficient for non-linear correlation; $P<0.0001$ $\left({ }^{* * *}\right)$; ns - not significant. g Kaplan-Meier overall survival curves of the Metformin-taking diabetic lung cancer patient cohort stratified by AXIN2 expression levels (mRNA threshold expression level $=1.02$, logrank test, $\left.P=0.046\left({ }^{*}\right)\right)$.

Next, we addressed the question whether regular intake of Metformin by diabetic cancer patients might have an impact on expression of SOX4 and other Wnt target genes in their tumor tissue. For this purpose, we analyzed a lung cancer patient cohort, as it has been shown that lung cancer is associated with aberrant Wnt signaling ${ }^{39}$. No significant changes in mean values of SOX4 and AXIN2 between non-diabetic and diabetic Metformin-taking lung cancer patients were detected (Supplementary Table S1). However, there was a significant correlation between SOX4 and AXIN2 mRNA levels in tumor tissues in the group of non-diabetic lung cancer patients (Spearman's rank correlation coefficient $\rho=0.47, P<0.0001$ ). This correlation was lost in tumor samples of the diabetic Metformin-taking lung cancer cohort (Fig. 1f). Since SOX4 expression and EMT are common mechanisms underlying metastasis ${ }^{26}$, we tested whether levels of EMT markers in lung tumor samples were also affected by Metformin intake. Indeed, there was a significant correlation between levels of $A X I N 2$ and the EMT markers $V I M$ (Vimentin) and ZEB1 (Zinc Finger E-Box Binding Homeobox 1), which again was lost in tumor samples from Metformin-taking lung cancer patients (Supplementary Fig. S2). Interestingly, within the Metformin-taking cohort, higher initial levels of AXIN2 mRNA ('high Wnt group') correlated with prolonged survival $(P=0.046)$ (Fig. 1g). We speculate that the high AXIN2 group represents Wnt-addicted tumors, suggesting that patients with higher Wnt signaling might particularly benefit from Metformin treatment.

\section{Metformin treatment abolishes TCF4/ $\beta$-catenin/CBP-p300 activation complex formation}

Next, we addressed whether TCF4 (T-cell Factor 4, a member of LEF/TCF protein family) remains bound to the SOX4 promoter upon Metformin treatment. We inspected the SOX4 gene locus and found four putative sites for LEF/ TCF transcription factors binding (containing the consensus sequence $\mathrm{CAAAG}^{40}$ ) within the $\mathrm{SOX} 4$ promoter region. Another four putative TCF4 binding sites were found in close proximity downstream in the gene body (Fig. 2a). By chromatin immunoprecipitation assay (ChIP) 


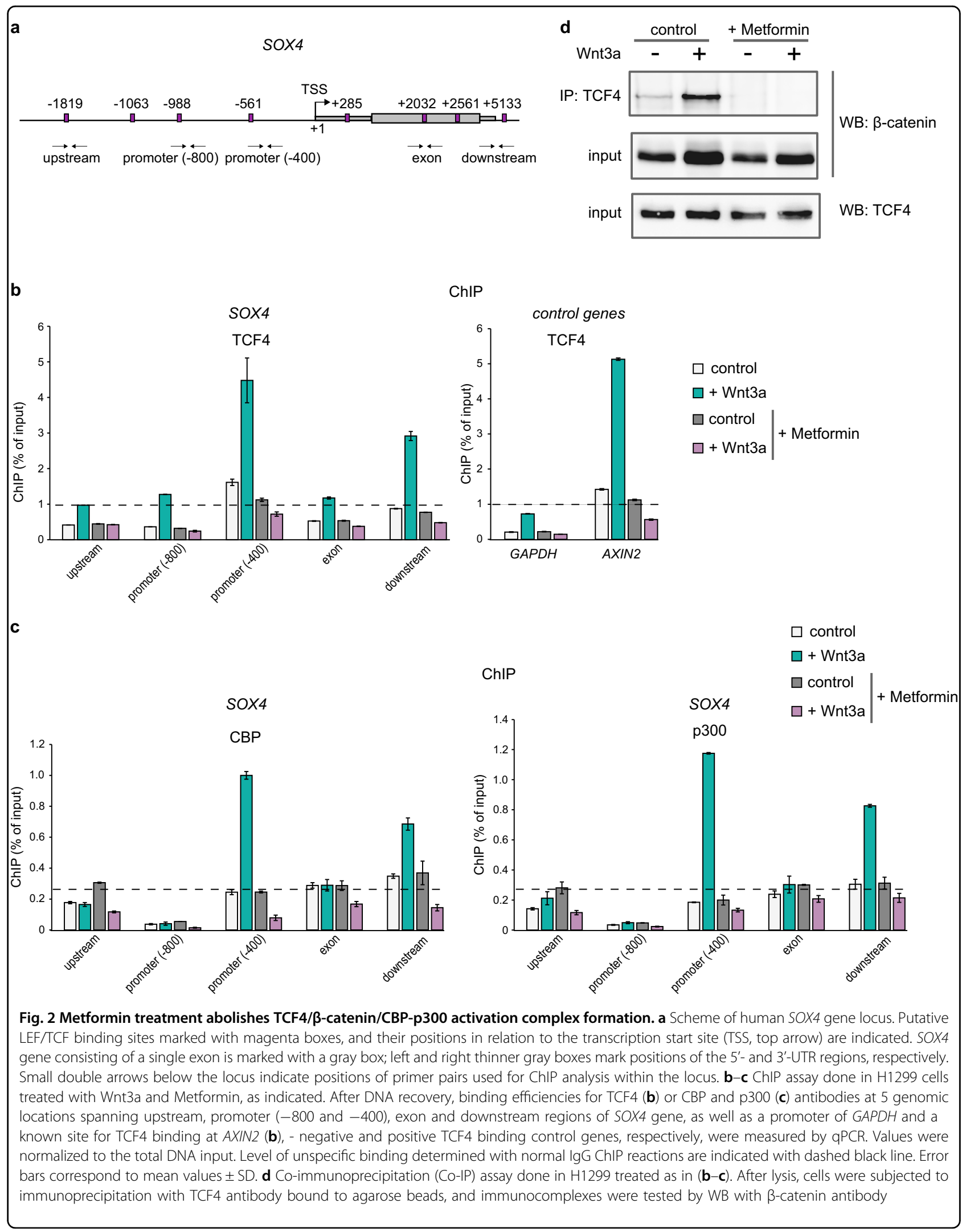


we found that, indeed, the proximal promoter of SOX4 gene (at position -400 from transcription start site (TSS)) strongly binds TCF4 upon treatment with Wnt3a. Similar binding was detected to $A X I N 2$, a positive control gene for TCF4 binding ${ }^{41}$, in contrast to a negative control, GAPDH gene. However, Metformin treatment completely abolished TCF4 binding, for both SOX4 and AXIN2 genes (Fig. 2b).

We then analyzed whether the mechanisms that have been proposed to underlie the antidiabetic effect of Metformin might also account for its anticancer properties. While previous studies have suggested that activation of AMPK mediates the anticancer action of Metfor$\min ^{10,11}$, this remains controversial ${ }^{12,13}$. In addition, Metformin has been shown to inhibit mitochondrial GPD $2^{14}$. In our experiments, however, neither siGPD2, nor siAMPK interfered with the Metformin'sinhibiting effect on SOX4 expression (Supplementary Fig. S3a-b). Metformin has also been shown to reduce gene activation in gluconeogenesis by promoting phosphorylation of the histone acetyltransferase (HAT) CBP, but not of the related HAT $\mathrm{p} 300^{42}$. CBP (also known as CREB-binding protein or CREBP) and p300 (p300 known as EP300 or E1A binding protein $\mathrm{p} 300$ ), share $63 \%$ homology in their sequences and structures and are involved in multiple cellular processes functioning as transcriptional co-factors and histone acetyltransferases ${ }^{43}$. It has been shown that Metformin treatment causes phosphorylation of murine CBP at Ser436 blocking its binding to promoters of gluconeogenesis enzymes genes, whereas p300, which has Ala instead of Ser at this position, retains its activity ${ }^{42}$. We assayed whether Metformin utilizes its effect on SOX4 in similar fashion and exclusively prevents CBP binding at the promoter of SOX4 gene over p300. We found that Metformin treatment abrogated binding to the SOX4 promoter of both, CBP and p300 (Fig. 2c), arguing against CBP as Metformin's specific target in SOX4 inhibition. Moreover, by Co-immunoprecipitation assay (Co-IP), we found that TCF $4 / \beta$-catenin complex formation is affected by Metformin treatment in general, as this interaction induced by Wnt3a, was disrupted by the drug (Fig. 2d).

\section{DDIT3 is one of the key mediators of Wnt signaling inhibition}

The inhibition of TCF4 binding to target gene promoters accompanied by removal of $\mathrm{CBP} / \mathrm{p} 300$ suggested that Metformin might induce some transcriptional repressor. We focused on the stress response transcription factor DDIT3 (DNA damage-inducible transcript 3, CHOP, GADD153), since it is known to be Metformininducible $^{44}$ and inhibiting Wnt signaling via LEF/TCF binding ${ }^{45}$. We found that in concentrations where Metformin induces DDIT3 protein (Supplementary Fig. S4ac), it repressed Wnt signaling (Supplementary Fig. S4d). In a loss-of-function approach, siDDIT3 blocked the ability of Metformin to inhibit SOX4 induction by Wnt3a (Fig. 3a and Supplementary Fig. S5a). Using a DDIT3-mutant H1975 cell line created by CRISPR/Cas9 gene editing, we found that DDIT3 knockout completely abrogated SOX4 inhibition by Metformin (Fig. 3b and Supplementary Fig. S4e). Conversely, DDIT3 overexpression in three different cell lines using the Tet-on system inhibited SOX4 expression, thus mimicking the effect of Metformin (Fig. 3c). This suggests that DDIT3 induction directly mediates SOX4 inhibition by Metformin. Indeed, the DDIT3 inducers, Tunicamycin ${ }^{46}$ and Bortezomib ${ }^{47}$, also blocked SOX4 expression (Fig. 3d and Supplementary Fig. S6a-b). Additionally, consistent with inhibition of SOX4, a gene promoting metastasis and cell invasion ${ }^{22}$, both Metformin and Bortezomib significantly reduced the invasion characteristics of cancer cells induced with Wnt3a treatment (Supplementary Fig. S6c).

Both Tunicamycin and Bortezomib induce endoplasmic reticulum (ER) stress, and DDIT3 is a component mediating the Unfolded Protein Response $(\mathrm{UPR})^{48}$. We examined whether other key components of the UPR might also mediate Metformin's action. Indeed, targeting the other UPR components (PERK, IRE1, ATF2, ATF4, and ATF6) by siRNA also repressed Metformin's ability to block SOX4 induction by Wnt3a, with ATF6 being the most prominent (Fig. 3e and Supplementary Fig. S5b).

\section{Metformin and $\mathrm{MCl}$ inhibitors cause intracellular acidification and induce the UPR}

How does Metformin induce the UPR? We and others ${ }^{49}$ observed that culture media from cells under Metformin treatment tended to acidify. Hence, we hypothesized that Metformin treatment might also disturb cells' ability to maintain the intracellular $\mathrm{pH}(\mathrm{pHi})$, thereby inducing ER stress and the UPR. It is known that the extracellular $\mathrm{pH}$ ( $\mathrm{pHe}$ ) in tumor microenvironment is reduced to as low as $\sim \mathrm{pH} 5.5$, and that acidosis is an important stress factor and selection force for cancer cell somatic evolution ${ }^{50}$. To test whether Metformin lowers the intracellular $\mathrm{pH}$, we generated a stable H1975 lung cancer and HEK293 control cell line expressing a $\mathrm{pH}$-sensitive variant of GFP (ECGFP) $\left(\mathrm{H} 1975^{\mathrm{EC}-\mathrm{GFP}}\right.$ and HEK293 $\left.{ }^{\mathrm{EC}-\mathrm{GFP}}\right)$, whose fluorescence is extinguished at low $\mathrm{pH}$ when excited at $488 \mathrm{~nm}$, but not at $405 \mathrm{~nm}$ (' $\mathrm{E}_{488}$ ' vs. ' $\left.\mathrm{E}_{405}\right)^{51}$. Metformin treatment strongly reduced emission at $\mathrm{E}_{488}$, but not at $\mathrm{E}_{405}$, indicating lowering of $\mathrm{pHi}$, and this was specific for the H1975 ${ }^{\text {EC-GFP }}$ lung cancer cell line (Fig. 4a). We also established a human colon cancer cell line DLD1 expressing a combination of $\mathrm{pH}$ sensitive EC-GFP, as a $\mathrm{pHi}$ sensor, along with a $\mathrm{pH}$-insensitive protein mCherry, as a control fluorescent protein (DLD1 ${ }^{\text {EC-GFP/mCHERRY }}$. Using this reporter cell line, we analyzed the $\mathrm{pHi}$ dynamics with and without Metformin treatment. Cells 

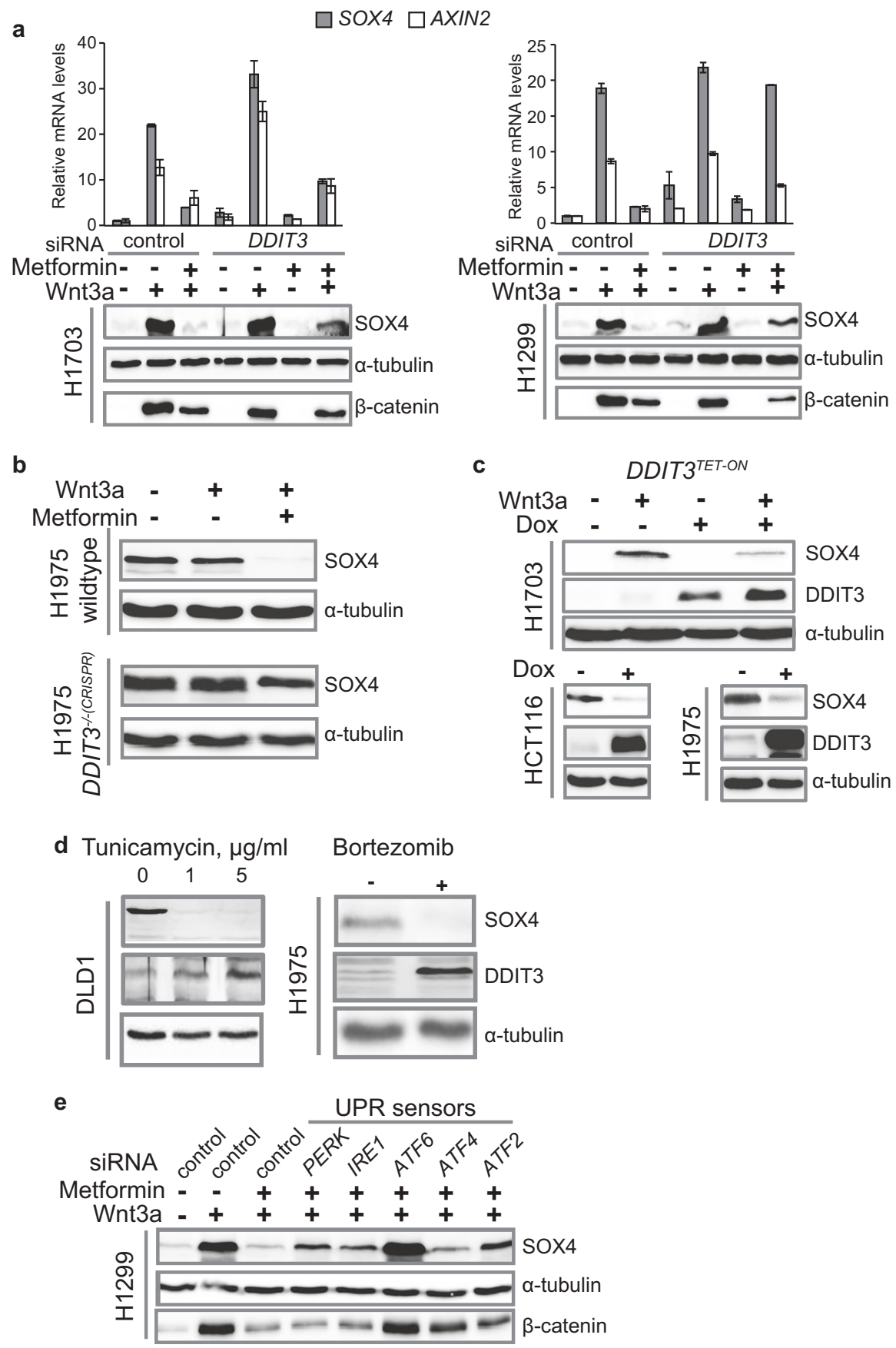

Fig. 3 DDIT3 is a key mediator of SOX4 repression and Wnt signaling inhibition. a-e Levels of the indicated mRNA and proteins in the indicated cell lines were monitored by qRT-PCT or WB, respectively. a SOX4 rescue by DDIT3 loss-of-function. Error bars represent mean values \pm SD. $\mathbf{b}$ SOX4 rescue in cells with DDIT3 knockout (DDIT3 $\left.{ }^{-1-(C R I S P R}\right)$ in comparison to wildtype. Metformin treatment - $35 \mathrm{~h}$. c SOX4 inhibition caused by overexpression of DDIT3 in DDIT3 TET-ON cells induced by Doxycycline (Dox). $\mathbf{d}$ DDIT3 induction and removal of SOX4 protein caused by ER drugs, Tunicamycin and Bortezomib. e SOX4 rescue caused by siRNA-mediated knockdown of the indicated members of the UPR.

were placed in slightly acidic medium (pH 6.5) mimicking acidified tumor microenvironment. Without Metformin, cancer cells predictably increased the $\mathrm{pHi}$ to compensate lower pHe (Fig. 4b, control) ${ }^{52}$, however, in the presence of Metformin the pHi was significantly decreased.
Next, we assayed the pHi changes in tumor tissue derived from human lung cancer $\mathrm{H} 1975^{\mathrm{EC}-\mathrm{GFP}}$ cells xenotransplanted in nude mice that were given Metformin orally, once the tumor growth was detected. A week later after the treatment had started, mice were subjected 


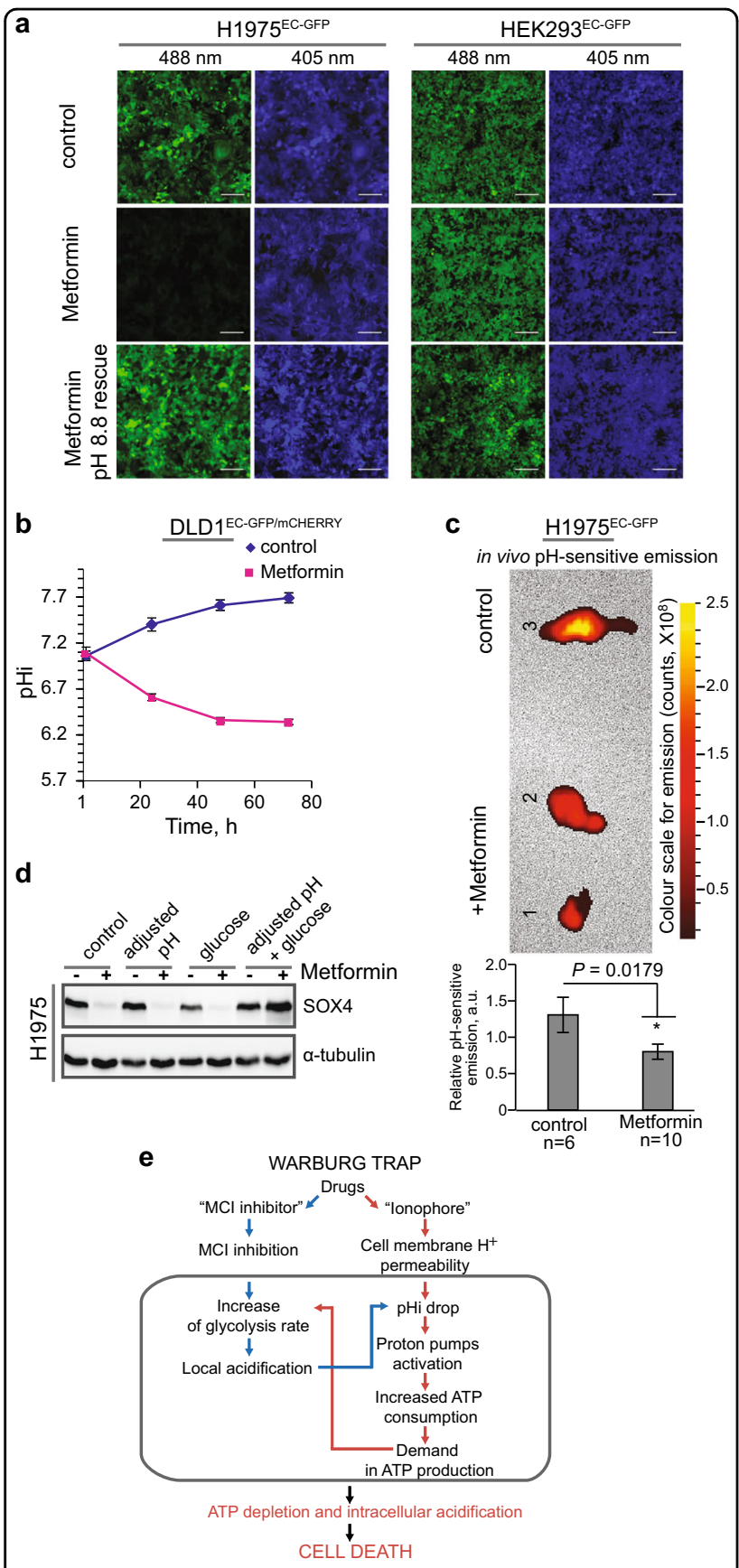

Fig. $4 \mathrm{MCl}$ inhibitors cause intracellular acidification. a Intracellular acidification monitored by live imaging in the indicated cell lines upon treatment with Metformin (48 h). After imaging, cells were transferred to media with $\mathrm{pH} 8.8$ supplemented with $5 \mu \mathrm{M}$ Nigericin, for $0.5 \mathrm{~h}$, before re-imaging (Metformin pH 8.8 rescue). Scale bar, $150 \mu \mathrm{m}$. b Intracellular acidification time-course caused by Metformin treatment in DLD1 ${ }^{\text {EC-GFP/ }}$ mCHERRY cells. c In vivo intracellular acidification caused by Metformin monitored in mouse tumor xenografts induced with $\mathrm{H} 1975^{\text {EC-GFP }}$ cells. Top: representative ex vivo xenograft images: tumors 1, 2-Metformin treated, tumor 3-control. Bottom: live animals pHi measurements, $P=$ $0.0179\left(^{*}\right)$; n number of animals. $\mathbf{d}$ SOX4 evaluation by WB after pH adjustment to 7.4 and $4 \mathrm{mM}$ glucose replenishment of culture media upon treatment $\mathrm{H} 1975$ cells with Metformin. e Warburg Trap principle scheme (b-c): Error bars correspond to mean values \pm SEM to live imaging, and $\mathrm{pH}$ sensitive fluorescence of tumor cells was monitored, first in vivo (Fig. 4c, bottom) and then ex vivo, immediately after tumor excision (Fig. 4c, top). We detected, both in vivo and ex vivo, a significant $(P=0.0179) \mathrm{pHi}$ drop in tumor tissues of tested animals that received Metformin compared to the control mice. We conclude that Metformin significantly decreases the intracellular $\mathrm{pH}$ in cancer cells, both in vitro and in vivo.

How does the treatment with Metformin affect the pHi? Metformin inhibits Mitochondrial Complex I (MCI) ${ }^{4}$ and hence ATP production, leading to compensatory increase in glycolysis and acidification due to lactic acid production. We tested the effect on pHi of other known MCI inhibitors and found that, similar to Metformin, all caused a pHi drop (Supplementary Fig. S7a-b). However, this was not the case with an inhibitor of Mitochondrial complex II (Supplementary Fig. S7c), which produces less energy than complex I. Of note, MCI inhibitors are known for their anticancer properties $^{16-18}$.

A common feature of cancer cells is a reversed $\mathrm{pH}$ gradient, i.e., a higher $\mathrm{pHi}$ and a lower $\mathrm{pHe}$ than in normal cells because their $\mathrm{pHi}$ homeostasis relies on extrusion of $\mathrm{H}^{+}$by ATP-consuming proton pumps ${ }^{53,54}$. In case of an ATP deficit, proton pumps function is impaired leading to intracellular acidification. This scenario predicts that cancer cells might overcome Metformin inhibition when extra glucose is provided to support glycolysis as an alternative pathway for ATP production. Indeed, cell culture medium $\mathrm{pH}$-adjustment combined with elevated glucose completely rescued SOX4 suppression by Metformin (Fig. 4d). This result is consistent with the earlier observation that cancer cells are more sensitive to Metformin at lowered glucose levels ${ }^{49}$.

To address a question whether the intracellular acidification alone would block Wnt signaling and cause similar effects as MCI inhibitors, we tested drugs thought to decrease $\mathrm{pHi}$ by affecting monocarboxylate transporters $(\mathrm{MCT})$ and carbonic anhydrases $(\mathrm{CA})^{54}$. We found that a broad MCT inhibitor CHC (2-Cyano-3-(4-hydroxyphenyl)-2-propenoic acid) was able to decrease $\mathrm{pHi}$ (Supplementary Fig. S8a), and this correlated with its Wnt signaling inhibition ability (Supplementary Fig. S8b). However, specific MCT-1 (AZD3965) or CA inhibitors (Azetazolamide) were not able to drop the pHi or inhibit Wnt signaling (Supplementary Fig. S8). We therefore conclude that any treatment causing pHi drop would inhibit Wnt signaling.

\section{$\mathrm{MCl}$ inhibitor and ionophore drug combinations inhibit Wnt signaling and cell viability}

We reasoned that combined treatment with $\mathrm{MCI}$ inhibitor and $\mathrm{H}^{+}$-ionophore could create an auto-enhancing cycle of acidification that would specifically target tumor cells. The specificity of this treatment regime for cancer 


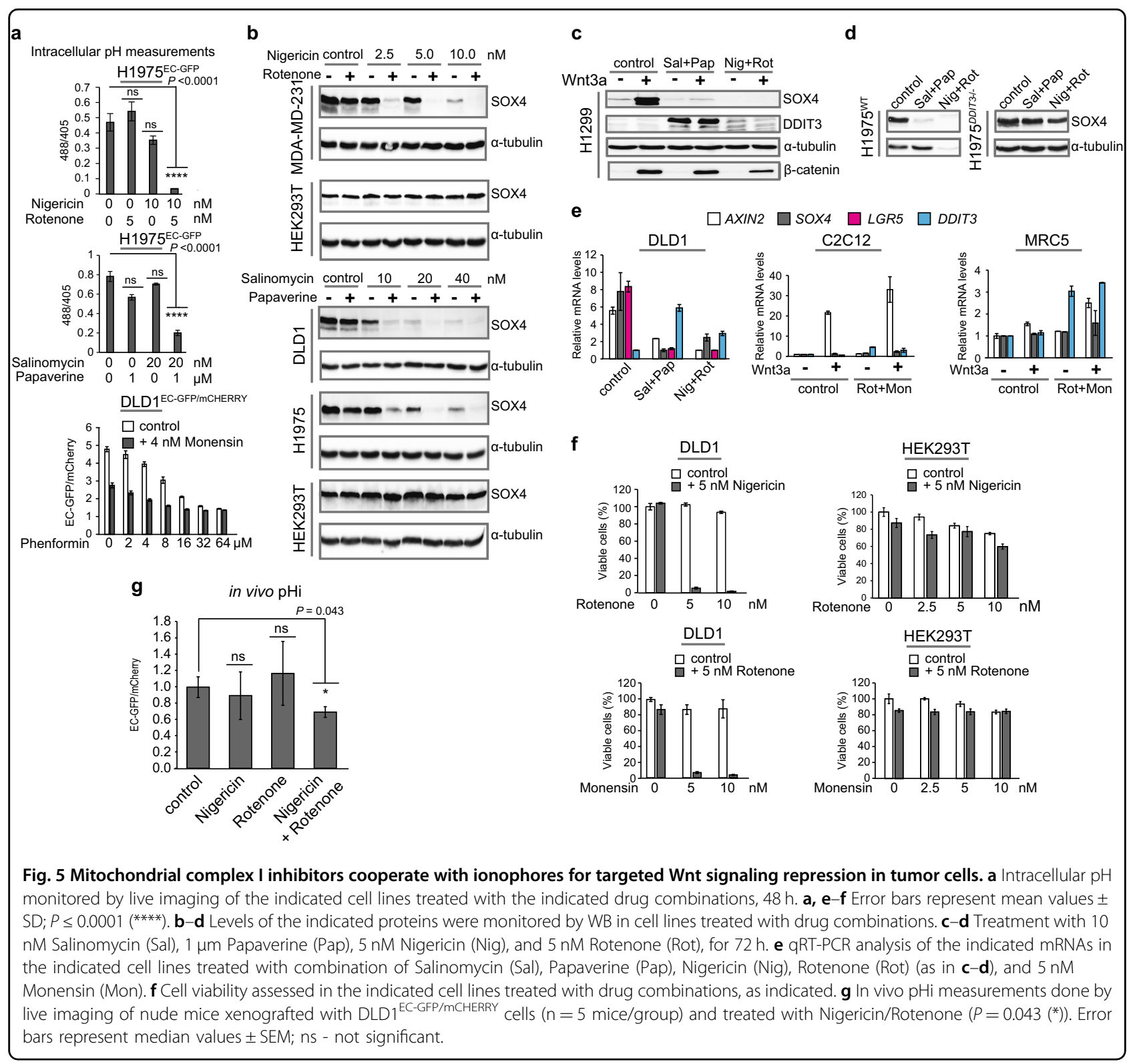

cells would come from (i) their reverse $\mathrm{pH}$ gradient and (ii) that they rely mostly on glycolysis as a source of ATP (the Warburg effect), thereby producing acidifying lactic acid. Upon ionophore-induced extra-to-intracellular proton leakage, cancer cells would consume more glucose to aliment proton pumps counteracting acidification, thus producing even more lactic acid, and thereby escalating cancer cells into hyper-acidification and ATP depletion. We named a principle comprised by this cycle as a 'Warburg Trap' (Fig. 4e).

We tested this hypothesis by treatment of cancer and non-cancer cell lines with selected drug combinations: Nigericin (ionophore) with Rotenone (MCI inhibitor),
Salinomycin (ionophore) with Papaverine (MCI inhibitor), and Monensin (ionophore) with Phenformin (MCI inhibitor). We confirmed that these drug combinations lowered pHi in vitro (Fig. 5a, and Supplementary Fig. S9a). Predictably, the drug combinations cooperatively blocked constitutive and Wnt3a-induced SOX4 expressions in cancer cell lines (Fig. 5b-c, and Supplementary Fig. S9b-c), and this effect was rescued in DDIT3 ${ }^{-/}$cells (Fig. $5 \mathrm{~d}$ ).

Additionally, we observed that DDIT3 was expressed only transiently. When cells were treated with the drug combinations for $24 \mathrm{~h}$, DDIT3 protein induction was detected simultaneously with SOX4 repression in H1299 cells. However, $24 \mathrm{~h}$ later (at $48 \mathrm{~h}$ post-treatment), DDIT3 
was undetectable (Supplementary Fig. S9c). Importantly, SOX4 remained repressed, even in the absence of detectable DDIT3.

Then, the drug combination treatment blocked aberrant Wnt signaling in DLD1 cells bearing APC mutation, with no effect in non-cancer cell lines (C2C12 and MRC5), manifested by strong decrease of expression of Wnt target genes, AXIN2 and LGR5. LGR5 is a colon and lung cancer stem cell marker ${ }^{55,56}$, and its expression reflects stemnesslike properties of cancer cells (Fig. 5e and Supplementary Fig. S9d). Moreover, we confirmed that the drug combinations reduced the ATP levels in cancer cells, but not in non-cancer cell lines (HEK293T and MRC5, Supplementary Fig. S9e). DDIT3 is also a potent inducer of apoptosis $^{48}$, and the selected drug pairs strongly cooperated in reducing viability of various cancer cell lines of different origin, with no substantial effect in non-cancer cell lines (Fig. 5f, and Supplementary Fig. S10a). We ruled out that this effect was mediated by reactive oxygen species (ROS) (Supplementary Fig. S10b).

Finally, the Nigericin/Rotenone combination lowered pHi in vivo $(P=0.043)$ in a xenograft tumor model with DLD1 ${ }^{\text {EC-GFP/mCHERRY }}$ colon cancer cells (Fig. $5 \mathrm{~g}$ ), therefore, providing an additional evidence that the drug combination utilized the same mechanism in vivo that was found for Metformin (Fig. 4c). Mechanistic interactions of the components causing inhibition of Wnt signaling are summarized in Fig. 6. Combination of dual effects on cellular membrane property and energy metabolism provides a unique opportunity for cancer cell specific targeting. Upon treatment (that lasts about 3 days for the most of the tested cell lines), differences between normal and cancer cells become more and more pronounced in terms of ATP level and pHi. We assume that this causes multiple proteins misfolding in the acidified intracellular compartment inducing the UPR and DDIT3, blocking Wnt signaling and activating apoptosis.

\section{Discussion}

In this study, we established that SOX4 is induced by Wnt signaling in number of human cancer cell lines of different entities (Fig. 1). It has been shown before that SOX4 also mediates TGF $\beta$ signaling during cancer progression $^{57,58}$. This relevance to cancer development, involvement in at least two major cancer cell signaling pathways - Wnt and TGF $\beta$ - makes SOX4 a good candidate to be used as a marker gene suitable for assessment of anticancer treatments. Using SOX4, we discovered that Metformin acts as Wnt signaling inhibitor (Fig. 2 and Fig. 3). We also revealed an ability of Metformin to trigger pHi drop in live cells in vitro and in vivo (Fig. 4a-c). We speculate that this effect underlies the universal anticancer property of Metformin. Despite earlier observations concerning acidification caused by Metformin ${ }^{49,59}$, its ability to induce DDIT3 ${ }^{44}$, its MCI inhibitor property ${ }^{60}$, and ability to deplete $\mathrm{ATP}^{15}$, a thorough analysis of intracellular $\mathrm{pH}$ dynamics upon Metformin treatment had not been performed. Applying live cell intracellular $\mathrm{pH}$ sensor assay, we found that any other tested MCI inhibitors also induced pHi drop (Supplementary Fig. S7a). A straightforward conclusion about reduction of ATP levels due to inhibition of $\mathrm{MCI}^{15}$ led us to an idea that ATP depletion would therefore impair defendant proton pumps function. This in turn would lead to misbalance between $\mathrm{H}^{+}$leakage from outer acidified microenvironment to intracellular compartment and enhanced requirement for extrusion $\mathrm{H}^{+}$to outer space. We can speculate that a similar effect on $\mathrm{pHi}$, albeit to lesser extent, could also underlie the anti-diabetes properties of Metformin. Consistent with this idea, it has been reported that other MCI inhibitors also have anti-diabetic properties $^{61}$.

Additionally, we found that inhibition of Wnt signaling by intracellular acidification was not exclusive to $\mathrm{MCI}$ inhibitors. Inhibition of lactic acid extrusion by a broad MCT inhibitor was able to lower pHi and block Wnt signaling (Supplementary Fig. S8). This suggests that any treatment resulting in the pHi drop would also block Wnt signaling.

Mechanistically, intracellular acidification inhibits Wnt signaling via the Unfolded Protein Response linked to the drop of ATP level. Intracellular acidification induces DDIT3, an endogenous Wnt signaling inhibitor (Fig. 3 and Supplementary Fig. S4a-c), which disrupts the TCF4/ $\beta$-catenin activation complex (Fig. 2d). In addition, upon acidification, binding of TCF4, as well as $\mathrm{CBP} / \mathrm{p} 300$, to SOX4 promoter was impaired (Fig. 2). These events blocked the Wnt response, and importantly, regardless of $\beta$-catenin accumulation (Fig. 1a and Fig. 5c), possibly involving $\beta$-catenin-independent Wnt/STOP signaling ${ }^{62}$. DDIT3 induction upon drug treatments was transient (Supplementary Fig. S9c), while the inhibition of Wnt signaling was persistent. This suggests that additional components of the UPR or the apoptotic cascade induced by DDIT3 ${ }^{63}$ are involved in persistent Wnt signaling suppression and growth inhibition in cancer cell lines (Fig. $5 \mathrm{f}$ and Supplementary Fig. S10a).

Previously, Metformin's suppressive effect on triple negative breast cancer cells was linked to KLF5 transcription factor degradation through drop of cAMP and inactivation of PKA ${ }^{64}$. Intracellular acidification and ATP depletion could be upstream events that target to degradation not only SOX4 but also other transcription factors, such as KLF5.

Based on insights into a link between MCI inhibitors and intracellular $\mathrm{pH}$, we suggested an auto-enhancing cycle inflicted by a combination of ionophore and $\mathrm{MCI}$ inhibitor drugs, which would specifically entrap cancer 


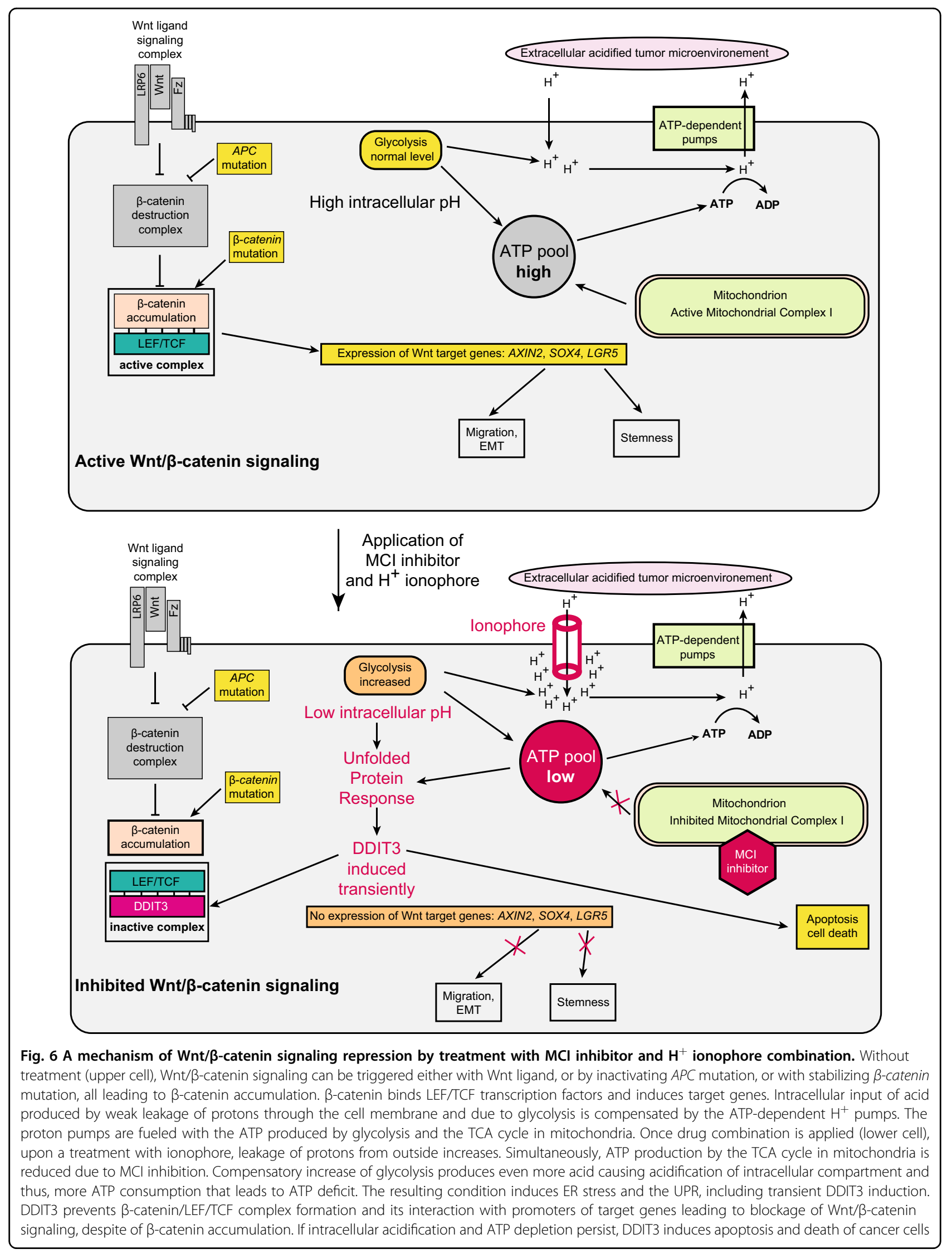


cell, - a 'Warburg Trap'. Why would MCI inhibitors affect glycolysis-addicted cancer cells? The phenomenon of cancer cells being more sensitive to mitochondrial inhibitors compared to non-cancer ones does not have a clear explanation yet $^{65}$. Recently, it has been found that in cancer cells the ratio between glycolysis and OXPHOS rates depend on $\mathrm{pHe}$ : the more acidic $\mathrm{pHe}$ is in tumor environment, the further cellular metabolism is shifted towards OXPHOS from glycolysis ${ }^{66}$. Similarly, it has been observed that local lactic acidosis in tumor tissue promotes a transition to a non-glycolytic mode ${ }^{67}$. MCI inhibitory component of the Warburg Trap restricts cancer cell from escaping towards OXPHOS, when the microenvironment is acidified. Upon such a treatment, tumor cells experience both a low pHi and drop in ATP level, leading to cell death.

We provide a molecular mechanism for the Warburg Trap action: the pHi drop induced by ionophore drug is accompanied by loss of ATP (Supplementary Fig. S9e). This in turn induces ER stress with subsequent DDIT3 induction by the UPR (Fig. 5c). The role of DDIT3 as endogenous Wnt inhibitor is currently underestimated because of misinterpreted observation on the absence of clear loss-of-function (LOF) phenotype in development of Xenopus laevis ${ }^{45}$ and mouse embryos ${ }^{68}$. Indeed, DDIT3 LOF was found to have an effect only upon ER stress. Consistent with this, DDIT3 mediates Metformin and the Warburg Trap effects only once the UPR is activated (Fig. 3a-c and Fig. 5d).

While our results strongly support a conclusion about specificity of the Warburg Trap towards cancer cells, the results suggest that this was not exclusively via Wnt inhibition, since SOX4 was repressed regardless of whether its expression is controlled by Wnt or other cell signaling pathways, such as TGF $\beta$ (Fig. 1b-c and Supplementary Fig. S1e), and this is consistent with DDIT3 being a global transcriptional repressor with a range of effects. Yet, Wnt signaling might be more sensitive to the treatment by Metformin and the Warburg Trap drugs in comparison to other pathways, since it is predominantly affected in diabetic lung cancer patients taking Metformin (Fig. 1f-g and Supplementary Fig. S2), and those with Wnt-addicted tumors had prolonged survival upon Metformin intake (Fig. 1g). We therefore suggest that postsurgery treatment with $\mathrm{MCI}$ inhibitors alone or as the Warburg trap drug combinations could be considered as a supportive therapy component, especially in cases of patients with tumors scored high for Wnt signaling, to prevent their tumor recurrence risk. This would be in agreement with earlier observations on beneficial effect of Metformin treatment for cancer patients ${ }^{69}$. A selective action of Metformin on Wnt-dependent tumors may help explain discrepancy in studies demonstrated reporting on no or negative effects of Metformin intake in diabetic cancer patients, e.g., in case of non-small cell lung cancer, NSCLC 9 .

The main limitation for use of Metformin as an anticancer drug is a requirement to apply it at very high concentrations to achieve a significant impact in cancer cells in vitro. As an alternative $\mathrm{MCI}$ inhibitor, Phenformin might also be considered. It was found to be well tolerated, and in our experiments was effective at lower concentrations than Metformin (Fig. 5a, and Supplementary Fig. S10a).

Could $\mathrm{H}^{+}$ionophores have a future to be used for cancer patients treatment? The $\mathrm{H}^{+}$ionophore Monensin is approved by FDA for application in veterinary as an anticoccidosis drug, and it displays no toxic effects in many different animals, with concentrations reaching 220 $\mathrm{nM}$ in plasma ${ }^{70}$ (that is 40 times higher than the concentrations applied in experiments described here (Fig. 5f, and Supplementary Fig. S10a)). Another anticoccidosis drug, $\mathrm{H}^{+}$ionophore Salinomycin, has been already tested on cancer patients, and encouraging results have been reported $^{71}$. Collectively, these data suggest that $\mathrm{H}^{+}$ ionophores have a good potential to be applied in human. Of note, application of $\mathrm{H}^{+}$ionophores, Nigericin and Salinomycin, has been already suggested for cancer stem cells targeting, and these drugs have been demonstrated to sensitize cancer stem cells ${ }^{72}$. Also, Salinomycin treatment has shown some promising results in medical practice $^{71}$. However, a specificity of such a single treatments remained unresolved.

Our provision of a molecular mechanism for the Warburg Trap raises the possibility to develop multiple further applications, which could also be combined with routine chemo- and radio-therapies. We speculate that the Warburg Trap could be used to overcome multiple drug resistance caused by ATP-dependent extrusion pumps. Such pumps (ABC transporters ${ }^{73}$ ) cannot be easily inhibited since they are required for normal cells de-toxication. However, the Warburg Trap approach could overcome this obstacle and provide targeted inhibition. Of note, ABCB1 and ABCG2 are Wnt-inducible transporters ${ }^{74}$ and therefore might be even more sensitive to the Warburg Trap inhibition.

In addition, the Warburg Trap principle for targeted anticancer drug design provides a basis for developing new-formula drugs with optimal pharmacological properties. Our findings therefore set a solid basis for in vivo experiments and development of pre-clinical investigations that would follow this study.

Collectively, our data provide the mechanistic rationale for a combination drug-based cancer cell specific approach to inhibit Wnt signaling downstream of $\beta$ catenin. This approach offers a new strategy for cancer cell specific treatment, especially for Wnt-addicted tumors such as a colon and lung cancer. 


\section{Materials and methods}

\section{Cells, constructs, chemicals, general procedures}

Human cell lines of lung: H1299, H1975, H1703, A549; colon: HCT116, DLD1; breast MDA-MB-231, and prostate PC3 cancers, glioblastoma-like U87MG and melanoma A375 were grown in RPMI (Lonza), supplemented with $11 \mathrm{mg} / \mathrm{ml}$ sodium pyruvate (Lonza). Murine B16F10 (melanoma) and $\mathrm{C} 2 \mathrm{C} 12$ (immortalized normal myoblast) cell lines, immortalized non-cancer human fetal lung fibroblast-like MRC5, non-cancer human embryonic kidney epithelial HEK293T, HEK293 and Phoenix Ampho human cell lines were grown in DMEM (Lonza). Culture media for all cell lines were supplied with $10 \%$ fetal calf serum (FCS; Biosera), and $11 \mathrm{mg} / \mathrm{ml}$ penicillin and streptomycin (PAA Laboratories $\mathrm{GmbH}$ ). For cancer cell lines, to imitate the pHe of tumor microenvironment, cell culture media were additionally supplemented with 20 $\mathrm{mM}$ PIPES and adjusted to $\mathrm{pH}$ 6.5; for non-cancer cell lines, to imitate $\mathrm{pHe}$ of non-tumor microenvironment, cell culture media were additionally supplemented with $20 \mathrm{mM}$ HEPES and adjusted to $\mathrm{pH} 7.5$.

Expression vectors for human LRP6, Xenopus tropicalis $\beta$-catenin, TOPFLASH-luciferase reporter were described before $^{75}$. Xenopus-wnt8-human-frizzled5 fusion construct $^{76}$, human DDIT3-luciferase reporter containing two copies of the C/EBP-ATF binding site in the AARE $(D D I T 3-L u c)^{77}$ and expression vector for Ecliptic EC$G F P^{51}$ were described before. pRenilla-TK (Promega) was a commercial construct. Human DDIT3 expression vector was generated by cloning DDIT3 ORF obtained by RTPCR using primers listed in Supplementary Table S2 from H1299 cells grown in the presence of Metformin for $48 \mathrm{~h}$, in $\mathrm{pCS}_{2}{ }^{+}$vector at $\mathrm{ClaI} / \mathrm{XbaI}$ restriction sites. It also was sub-cloned into a retroviral expression vector with a Tetinducible promoter pMOWSIN-TREl ${ }^{78}$. Resulting construct, pMOWSIN-TREl-DDIT3, was used in combination with pMOWS-rtTAM2 encoding the cDNA for trans-activator protein for retroviral transduction of selected cell lines using Phoenix Ampho packaging cell line, as described before ${ }^{79}$, and individual positive clones were selected with Puromycin, $48 \mathrm{~h}$ after transduction. To induce DDIT3 production, cells were treated with $5 \mu \mathrm{g} / \mathrm{ml}$ Doxycycline for $72 \mathrm{~h}$. To create cells expressing $\mathrm{pH}$ sensitive GFP variant, EC-GFP was sub-cloned in pMOWSneo-MCS retroviral vector ${ }^{80}$ at BamHI/EcoRI sites (with primers listed at Supplementary Table S2). Transduced cells (H1975 and HEK293) were selected with Neomycin, $48 \mathrm{~h}$ after transduction. To create pMOWS$E C-G F P / m C h e r r y$, Neo-resistance cassette was removed from pMOWS-Neo-EC-GFP construct with AfeI/HindIII and substituted with HindIII/ApaI-blunt fragment of $m$ Cherry from pcDNA3.1-H2b-mCherry (a gift from Robert Benezra (Addgene plasmid 20972)). The resulting construct was used for retroviral transduction in DLD1, and individual positive clones were screened for coexpression of GFP and mCherry with fluorescence microscope.

Induction with Wnt3a was performed by adding conditioned media (WntCM) at 1:4 ratios to the culture media for $48 \mathrm{~h}$ or as indicated, as described before $\mathrm{e}^{75}$.

\section{Drug treatments in cell culture}

In all experiments, unless stated otherwise, treatments were done using following conditions. Mitochondrial complex I inhibitors: Metformin - $6 \mathrm{mM}$ for $72 \mathrm{~h}$; Rotenone $-5 \mathrm{nM}$ for $48 \mathrm{~h}$; Papaverine $\mathrm{HCl}-0.5 \mu \mathrm{M}$ for $72 \mathrm{~h}$ or $1 \mu \mathrm{M}$ for $48 \mathrm{~h}$; Phenformin - as indicated, for $72 \mathrm{~h}$; Bay 87 2243 - as indicated, for $48 \mathrm{~h}$. Ionophores: Nigericin - 10 nM for $48 \mathrm{~h}$; Salinomycin - $10 \mathrm{nM}$ for $72 \mathrm{~h}$; Monensin - 5 $\mathrm{nM}$ for $48 \mathrm{~h}$. Other drugs were used at following concentrations and time periods, unless stated otherwise: Bortezomib - $20 \mathrm{nM}$ for $48 \mathrm{~h}$; Tunicamycin - 1-5 $\mu \mathrm{g} / \mathrm{ml}$ for $48 \mathrm{~h}$. Graviola leaves extract was prepared, as described before ${ }^{81}(100 \mathrm{mg} / \mathrm{ml}$ concentration corresponds to $100 \mathrm{mg}$ leaves extracted with $900 \mathrm{mg}$ DMSO) from powdered dry leaves of plant Annona muricata (Moringa Shop, Germany), applied at concentrations 0.01-0.16 $\mu \mathrm{g} /$ $\mathrm{ml}$, for $72 \mathrm{~h}$.

\section{D collagen invasion assay}

$3 \mathrm{D}$ collagen gels were prepared as described ${ }^{82}$. In brief, ice-cold $1 \mathrm{M}$ HEPES buffer, 0.7 M NaOH, 10× PBS pH 8.0 and bovine skin collagen $\mathrm{G}$ solution (L1613, Biochrome) were mixed in 1:1:2:16 ratios, respectively. $35 \mu \mathrm{l}$ of the resulting solution were added per well of a flat bottom 96well plate (BD 353376). A plate was kept overnight at $4{ }^{\circ} \mathrm{C}$ to allow gelation of the collagen. After gelation, 10,000 cells per well were seeded on top of the matrix, cultured overnight and stimulated with WntCM. $96 \mathrm{~h}$ later, cells were fixed with $3.7 \%$ PFA for $1 \mathrm{~h}$ and stained with Hoechst (Sigma). Imaging was performed using a LSM710 confocal microscope (Carl Zeiss) equipped with EC PlanNeofluar DIC 10×/0.3 NA objective lens (Carl Zeiss). For each well, a $2 \times 2$ tile z-stack was acquired. Image analysis was performed using Imaris software (Bitplane). Spots detection algorithm was applied to assign a spot for fluorescent intensity of each individual nucleus. Resulting spots were filtered by their z-position to separate collagen invaded cells from the cells remained on top of the matrix. Percentage of invaded cells was used as an output.

\section{Optical measurements of intracellular $\mathrm{pH}$}

The assay was done as described ${ }^{83}$. In brief, cell lines expressing $\mathrm{pH}$-sensitive EC-GFP or EC-GFP/mCherry, were densely seeded on 96-well flat-bottom plates (BD353376). The next day, cells were treated with drugs for $48 \mathrm{~h}$, or as indicated. Live cells were imaged using LSM710 confocal microscope (Carl Zeiss) equipped with 
EC Plan-Neofluar DIC 10×/0.3 NA objective lens (Carl Zeiss). For each well, $2 \times 2$ tile was acquired. In case of H1975 ${ }^{\text {EC-GFP }}$ and HEK293 ${ }^{\text {EC-GFP }}$ cell lines, $405 \mathrm{~nm}$ and $488 \mathrm{~nm}$ lasers were used for EC-GFP excitation, and emission light was collected using 535/50 filter for each laser. 488/405 ratios were quantified using ImageJ $(\mathrm{NIH})$ software. In case of DLD $1^{\text {EC-GFP/mCHERRY }}$ cell line, $485 \mathrm{~nm}$ (EC-GFP) and $538 \mathrm{~nm}$ (mCherry) excitation filters and $510 \mathrm{~nm}$ (EC-GFP) and $620 \mathrm{~nm}$ (mCherry) emission filters were used to collect EC-GFP and mCherry signals, respectively, using Fluoroscan Ascent microplate reader (Thermo Fisher Scientific). To convert 488/405 and 485/ 538 (EC-GFP/mCherry) ratios to $\mathrm{pHi}$ values, a calibration curve for each cell line was produced, as described ${ }^{84}$. In brief, untreated cells were exposed for $30 \mathrm{~min}$ to high $\mathrm{K}^{+}$ solutions with different $\mathrm{pH}(6.2-8.8$ range $)(140 \mathrm{mM} \mathrm{KCl}$, $1 \mathrm{mM} \mathrm{MgCl} 2,2 \mathrm{mM} \mathrm{CaCl} 2,5 \mathrm{mM}$ glucose buffered with either $40 \mathrm{mM}$ MES or $40 \mathrm{mM}$ Tris) containing $5 \mu \mathrm{M}$ Nigericin (Supplementary Fig. S7b, and data not shown). Each pHi measurement experiment was done with 5-7 biological replicates for every treatment.

\section{PLGA microspheres formulations preparation}

To ensure a continuous drug release and avoid high peak doses after bolus injections into animals, we used biodegradable polymer, PLGA (poly (lactic-co-glycolic acid)), as vehicle for the drug formulations. PLGA (lactid: glycolide (75:25)) (SIGMA or Vornia Biomaterials) formulations consisted of drug in the range of $5-20 \mathrm{mg}$ per $1 \mathrm{~g}$ of PLGA, as described elsewhere ${ }^{85,86}$. In brief, $100 \mathrm{mg}$ of PLGA beads were dissolved in $5 \mathrm{ml}$ Dichloromethane (DCM) together with the selected drug. PLGA/drug mixture was added drop-wise to $15 \mathrm{ml}$ of ice-cold $0.4 \%$ PVA (Polyvinylalcohol) water solution on ice, mixed for 1 $\mathrm{h}$ by rotation $(600 \mathrm{rpm})$ using magnet mixer. Formed emulsion was then left at room temperature on a mixer until DCM was evaporated (overnight) and subsequently washed three times with distilled water. Obtained microsphere beads were segregated according to their size by centrifugation for $5 \mathrm{~min}$ at $209 \mathrm{~g}$, followed by separation using a $250 \mu \mathrm{m}$ cell strainer (Thermo Fisher Scientific). After pelleting, beads were air-dried and additionally stored in vacuum for at least $24 \mathrm{~h}$, to ensure removal of traces of DCM. Finally, the beads were weighted and resuspended in sterile PBS for injections into animals.

\section{Animal experiments}

Animal care and all animal experiments were performed according to the national guidelines and were approved first by an institutional review board/ethics committee headed by the local animal welfare officer (Dr. Michaela Socher) of the German Cancer Research Center, Heidelberg, Germany. All experiments were in addition approved by the responsible national authority, the local
Governmental Committee for Animal Experimentation (Regierungspräsidium Karlsruhe, Germany) under licenses G244/11, G284/15, G195/16, and were carried out accordingly.

In vivo and ex vivo pHi measurements in xenograft tumors Five to six-week-old female NMRI-Foxn $1^{\text {nu }}$ (Charles River, Sulzfeld, Germany) were subcutaneously injected with $2 \times 10^{6} \mathrm{H} 1975^{\mathrm{EC}-\mathrm{GFP}}$ human lung cancer cells, resuspended in $100 \mu \mathrm{l}$ PBS into the right flank. Eighteen days after transplantation, once the tumor growth was detected, mice received drinking water containing $200 \mu \mathrm{g} /$ $\mathrm{ml}$ Metformin or normal drinking water, as a control, for 7 days. In vivo and ex vivo tumor imaging was performed with IVIS Lumina III (Perkin Elmer) system using $460 \mathrm{~nm}$ excitation and $520 \mathrm{~nm}$ emission filters and quantified with LivingImage software V4.4 (Caliper Life Sciences). For the experiment, in which $\mathrm{pHi}$ changes were induced with a combination of an ionophore and a MCI inhibitor, nude female mice were subcutaneously injected with $2 \times 10^{6}$ DLD1 ${ }^{\text {EC-GFP/mCHERRY }}$ cells resuspended in $100 \mu \mathrm{l}$ PBS. When the tumor diameter reached $5 \mathrm{~mm}$, mice were in vivo imaged with IVIS Lumina III, and the initial control GFP/mCherry ratios in xenografted tumors were measured using the appropriate filter sets. Animals were randomized into four cohorts ( $\mathrm{n}=5$ mice in each group), and were intraperitoneally injected, twice per week, either with $10 \mathrm{mg}$ of control PLGA microsphere preparations in $200 \mu \mathrm{l} \mathrm{PBS}$ alone, or with $5 \mathrm{mg}$ PLGA containing either 5 $\mu \mathrm{g}$ Nigericin/mg PLGA or $20 \mu \mathrm{g}$ Rotenone/mg PLGA beads, in $100 \mu \mathrm{l} \mathrm{PBS}$, or the combination of both compounds $(10 \mathrm{mg}$ of beads in $200 \mu \mathrm{l} \mathrm{PBS})$. One week later, animals were subjected to in vivo imaging, as described above. During live imaging, the animals were anesthetized with $5 \%$ initiating and $2 \%$ maintaining doses of isoflurane. EC-GFP/mCherry values were normalized to the control treatment and initial control signals.

\section{qRT-PCR}

RNA and cDNA were prepared as described ${ }^{87}$, and qRT-PCR was performed with UPL probes (Roche) using LC480 LightCycler (Roche). Details of qPCR primers and UPL probes used for amplification are provided in Supplementary Table S2. mRNA values were normalized to the housekeeping gene GAPDH (all in vitro experiments), or $E S D$ (patients' samples).

\section{Western blot analysis (WB)}

Cells were lysed in Triton lysis buffer (TBS $(50 \mathrm{mM}$ Tris pH7.4, $150 \mathrm{mM} \mathrm{NaCl}, 2.7 \mathrm{mM} \mathrm{KCl}), 1 \%$ Triton X-100, 2 $\mathrm{mM} \beta$-mercaptoethanol (ME), $1 \mathrm{mM} \mathrm{MgCl}_{2}, 1 \times$ proteinase inhibitor cocktail (PIC) (Sigma)) for $5 \mathrm{~min}$ on ice. Lysates were cleared by centrifugation and analyzed by SDS-PAGE. For $\beta$-catenin analysis, cytosolic extracts were 
prepared using Saponin lysis buffer (0.05\% saponin, $1 \mathrm{mM}$ $\mathrm{MgCl}_{2}, 1 \times \mathrm{TBS}, 2 \mathrm{mM} \mathrm{ME}, 1 \times \mathrm{PIC}$ ), for $30 \mathrm{~min}$ on ice. Antibodies used were: SOX4 (Diagenode cs-129-100), $\alpha-$ tubulin (Thermo Scientific, MS-581-P0), DDIT3 (Santa Cruz sc-575), $\beta$-catenin (BD Transduction Laboratories, 610153), and TCF4 (Santa Cruz, sc-166699).

\section{ChIP assay}

Chromatin immunoprecipitation assays were done essentially as described ${ }^{88}$, with some modifications. In particular, after fixation of cells with $1 \%$ formaldehyde for $10 \mathrm{~min}$, nuclei preparation and washing, chromatin was sheared in Shearing buffer $(25 \mathrm{mM}$ Tris- $\mathrm{HCl}, \mathrm{pH} 8.0 ; 1$ mM EDTA, $0.5 \mathrm{mM}$ EGTA, $2.5 \mathrm{mM}$ sodium pyrophosphate, $1 \mathrm{mM}$ PMSF, $1 \times$ PIC) using Covaris S2 (ultrasonicator with following settings: Time $=20 \mathrm{~min}, 20 \%$ Duty Cycle, Intensity $=4,200$ cycles per burst), or with Sonoplus Bandelin (12 times for $30 \mathrm{~s}$, 40\% power). Before immunoprecipitation, Triton X-100 to $1 \%$, SDS to $0.1 \%$ and $\mathrm{NaCl}$ to $150 \mathrm{mM}$ were added to the sheared chromatin. IP reactions were incubated overnight, and formed immunocomplexes were recovered using protein A/G magnetic beads (Pierce). After washings, complexes were eluted with Proteinase $\mathrm{K}$ digestion buffer (20 mM HEPES, $\mathrm{pH}$ 8.0, $200 \mathrm{mM} \mathrm{NaCl}, 1 \mathrm{mM}$ EDTA, 0.5\% SDS), and immunoprecipitated DNA was recovered after digestion with $400 \mu \mathrm{g} / \mathrm{ml}$ Proteinase $\mathrm{K}$ for $1 \mathrm{~h}$ at $42^{\circ} \mathrm{C}$, RNase A treatment and crosslinking reversal. DNA was purified and analyzed by qPCR analysis using SYBR Green master mix (Qiagen QuantiTect) with primers listed in Supplementary Table S2. CBP and p300 antibodies were from Santa-Cruz Biotechnology (sc-369X and sc-585X, respectively), TCF4 and normal IgG were from EMD Millipore (17-10109 and 12-370, respectively).

\section{Co-immunoprecipitation assay (Co-IP)}

Cells were lysed in Triton lysis buffer (TBS $(50 \mathrm{mM}$ Tris pH7.4, $150 \mathrm{mM} \mathrm{NaCl}, 2.7 \mathrm{mM} \mathrm{KCl}$ ), 1\% Triton X$100,1 \mathrm{mM} \mathrm{MgCl}, 1 \times$ proteinase inhibitor cocktail (PIC) (Sigma)) for $20 \mathrm{~min}$ on ice. Lysates were cleared by centrifugation at $2000 \mathrm{~g}$ and subjected to immunoprecipitation with TCF4 antibody (Millipore, 17-10109) bound to Protein A/G-PLUS agarose beads (Santa Cruz, sc-2003) overnight. After washing beads 6 times with washing buffer (TBS, $0.1 \%$ Triton X-100, PIC), immunocomplexes were eluted with Laemmli Sample Buffer $4 \times$ (Bio-Rad), resolved in SDS-PAGE and analyzed by WB.

\section{Patients' tumor samples}

All patients underwent a surgery at the Thoraxklinik, University Hospital Heidelberg.

RNA samples from lung tissues were provided by LungBiobank Heidelberg, a member of the BioMaterialBank
Heidelberg (BMBH), and the biobank platform of the German Center for Lung Research (DZL). All patients gave written informed consent for the use of their biomaterials for research purposes. The protocol was approved by the ethics committee of the University of Heidelberg. Tissues were snap-frozen within $30 \mathrm{~min}$ after resection and stored at $-80^{\circ} \mathrm{C}$ until the time of analysis. Tumor histology was classified according to the 3rd edition of the World Health Organization classification system $^{89}$. A brief summary of patients' clinical data is presented in Supplementary Table S1.

\section{Isolation of tissue samples RNA}

Total RNA was isolated using an RNeasy Kit (Qiagen, Hilden, Germany) according to the manufacturer's instruction, with the DNase I treatment step included. The quality of total RNA from patients' tissues was assessed with an Agilent 2100 Bioanalyzer and Agilent RNA 6000 Nano Kit (Agilent Technologies, Boeblingen, Germany). RNA was considered sufficient for further analyses if it had an RNA integrity number (RIN) of at least 8.0.

\section{Luciferase reporter assays}

Luciferase reporter assays were carried out in 96-well plates, as described before ${ }^{75}$. In brief, a total of $100 \mathrm{ng}$ of DNA was transfected per well, including either $5 \mathrm{ng}$ TOPFLASH with $1 \mathrm{ng}$ pRenilla-TK or $10 \mathrm{ng}$ human DDIT3-luciferase reporter (DDIT3-luc) and, when indicated, 4ng human LRP6, $4 \mathrm{ng}$ Xenopus-wnt8-humanfrizzled5 fusion, $0.5 \mathrm{ng}$ Xenopus tropicalis $\beta$-catenin and $70 \mathrm{ng}$ human DDIT3. Drug treatments were applied next day after transfection, and cells were treated for $48 \mathrm{~h}$ prior to luciferase activity measurements with the Dual luciferase system (Promega).

\section{Cell viability assay}

Indicated cells were treated with indicated drug combinations for $48 \mathrm{~h}$ in conditions imitating tumor environment, in case of cancer cell lines, or in conditions of non-tumor environment, in case of non-cancer cell lines. After the treatment, cells were analyzed for cell viability using CellTiter-Glo ${ }^{\circledast}$ Cell Viability Assay (Promega), according to the manufacturer's recommendations. For each treatment, fractions (\%) of viable cells were quantified, with untreated viable cells set as $100 \%$. Each experiment was repeated at least twice, with 6 biological replicates for each condition.

\section{Measurement of cellular ATP levels}

ATP levels were quantitated by the CellTiter-Glo ${ }^{\circledR}$ Cell Viability Assay kit (Promega), according to the manufacturer's recommendations. In brief, serial dilutions of ATP solutions were prepared, and the luminescence 
signal was recorded to build a calibration curve. Cells were treated, as described above for the cell viability assay, and an absolute ATP amount per cell was quantified using the calibration curve. Each measurement was repeated at least twice, with 6 biological replicates for each condition.

\section{siRNA transfection experiments}

For mRNA knock-down experiments, cells in 6-well format were transfected with $50 \mathrm{nM}$ of non-targeting control siRNA or with corresponding ON-TARGET SMARTpool siRNA or siGENOME SMARTpool siRNA (all from Dharmacon, except for DDIT3 siRNA, which was from Santa-Cruz) using DharmaFECT1 reagent (Dharmacon) following the manufacturer protocol. 24 $\mathrm{h}$ after siRNA transfection, the cells were treated with WntCM, and subjected to selected drug treatment, as indicated. Cells were harvested in $72-120 \mathrm{~h}$ post-transfection, depending on experiment, for Western blot and qRT-PCR analyses. For each experiment with siRNA transfection, mRNA knockdown efficiencies were quantified using qRT-PCR, and a targeted mRNA levels were found to be reduced down to at least 15-20\% of the one in a control treatment with non-targeting siRNA (Supplementary Fig. S4, and data not shown).

\section{CRISPR-mediated knock-out of DDIT3 gene}

H1975 cells were stably transfected with Cas9 under Blasticidin selection (pHCSVBlast-Cas9, Dharmacon). Positive clone was selected using detection of Cas9 in WB using Cas9 antibody (Novus NBP2-36440, clone 7A93A3). Cas9 expressing cells were transfected with a 1:1 molar ratio mix of tracrRNA (Dharmacon product U-002000-120) and DDIT3-specific crRNA (5'CUG GUAUGAGGACCUGCAAGGUUUUAGAGCUAUGCU GUUUUG 3', designed with CRISPR RNA Configurator tool, Dharmacon) using DarmaFECT1 (Dharmacon). 5 days later, cells were harvested and plated at low density. Individual clones were treated with DDIT3-inducing drugs and assayed by WB, $48 \mathrm{~h}$ later (Supplementary Fig. S5e). Clone that failed to produce DDIT3 protein, was selected and verified with successive sequencing. The effective mutation is highlighted in Supplementary Fig. S5e.

\section{Statistical analysis}

GraphPad Prism software was used for most statistical analyses. Two-way ANOVA tests were used to assess statistical significance in cell invasion, $\mathrm{pHi}$ properties between treated and untreated cell lines in vitro. In vivo changes of $\mathrm{pHi}$ in tumor xenograft tissues were tested with unpaired $t$-test. Cell invasion properties and ATP amount changes were assessed using one-way ANOVA Dunnett's multiple comparison tests.
Correlations between expression of mRNA of interest and of Wnt target genes in patients' tumor samples were carried out using non-parametric correlation tests, and Spearman's rank correlation coefficients were calculated. For assessment of patients' survival data, Kaplan-Meier curves were built, and log-rank (Mantel-Cox) test was calculated using IBM SPSS statistics software (V22.0). For finding an optimal cut-off level and survival data stratification, ADAM statistical software package (DKFZ, Heidelberg) utilizing Critlevel procedure was used ${ }^{90}$. In brief, for the combined patients cohort (including both Metformin-taking and not taking Metformin lung cancer patients), the optimal expression cut-off levels for the tested genes were calculated and used as new variants $(0=$ below threshold, $1=$ above threshold $)$, and these parameters were applied to assess the survival data. Only for the Metformin-taking lung cancer patients cohort stratification by AXIN2 expression (with a cut-off at 1.02), and not for the other tested genes, revealed differences in their survival that were found to be significant $(P=0.046)$.

\footnotetext{
Acknowledgements

This work was supported by the DFG CRC 1324. Support by the DKFZ Light Microscopy Facility and the DKFZ Central Animal Facility is gratefully acknowledged. We thank Philippe Lucarelli and Martin Böhm for their work on the preliminary data, and the technical staff of the Tumor Models Unit for the help with animal experiments.
}

\section{Author details}

${ }^{1}$ Division of Epigenetics and Cancer Risks Factors, German Cancer Research Center, Heidelberg D-69120, Germany. ²DNA vectors, German Cancer Research Center, Heidelberg D-69120, Germany. ${ }^{3}$ Division of Systems Biology and Signal Transduction, German Cancer Research Center, Heidelberg D-69120, Germany. ${ }^{4}$ Translational Lung Research Center Heidelberg (TLRC), German Center for Lung Research (DZL), Heidelberg, Germany. ${ }^{5}$ Tumor Models Unit, Center for Preclinical Research, German Cancer Research Center, Heidelberg D-69120, Germany. ${ }^{6}$ Division of Molecular Embryology, DKFZ-ZMBH Allianz, German Cancer Research Center, Heidelberg D-69120, Germany. ${ }^{7}$ Translational Research Unit, Thoraxklinik at University Hospital Heidelberg, Heidelberg D69126, Germany. ${ }^{8}$ Institute of Pathology, Heidelberg University Hospital, Heidelberg 69120, Germany. ${ }^{9}$ Department of Molecular Biology, University of Salzburg, Salzburg 5020, Austria. ${ }^{10}$ Cancer Cluster Salzburg, Salzburg 5020, Austria. ${ }^{11}$ Institute of Molecular Biology (IMB), Mainz 55128, Germany

\section{Authors contributions}

AG conceived, designed and supervised the project. SM, DD, and AG designed and performed most of the experiments. PS provided technical support for samples analysis by Western blotting and qRT-PCR. SD and AG did cloning and S2-classified experiments. SD, MM, AW, MT, and TM provided administration, provision of study materials and clinical data from patients. KMD legalized and conducted animal experiments. AR, CP, UK, and CN provided administration and financial support for the project. SM and AG wrote the manuscript. CN provided funding, advised, and re-wrote the manuscript. All authors discussed the data, read, commented and approved the manuscript.

Conflict of interest

SM, DD, CN, and AG are inventors on a patent application EP16174558. Other authors declare no competing financial interest.

Supplementary Information accompanies the paper at (https://doi.org/ 10.1038/s41421-018-0033-2). 
Received: 9 November 2017 Revised: 18 April 2018 Accepted: 18 April 2018 Published online: 03 July 2018

\section{References}

1. Jung, Y. S., Park, C. H., Eun, C. S., Park, D. I. \& Han, D. S. Metformin use and the risk of colorectal adenoma: a systematic review and meta-analysis. J. Gastroenterol. Hepatol. 32, 957-965 (2017).

2. Benjamin, D., Colombi, M., Hindupur, S. K. \& Betz, C. Syrosingopine sensitizes cancer cells to killing by metformin. Sci. Adv. 2, e1601756 (2016).

3. Morgillo, F. et al. Synergistic effects of metformin treatment in combination with gefitinib, a selective EGFR tyrosine kinase inhibitor, in LKB1 wild-type NSCLC cell lines. Clin. Cancer Res.: Off. J. Am. Assoc. Cancer Res. 19, 3508-3519 (2013).

4. Liu, J. et al. Enhanced cytotoxic effect of low doses of metformin combined with ionizing radiation on hepatoma cells via ATP deprivation and inhibition of DNA repair. Oncol. Rep. 28, 1406-1412 (2012).

5. Samsuri, N. A. B., Leech, M. \& Marignol, L. Metformin and improved treatment outcomes in radiation therapy-a review. Cancer Treat. Rev. 55, 150-162 (2017).

6. Zhong, S., Wu, Y., Yan, X., Tang, J. \& Zhao, J. Metformin use and survival of lung cancer patients: meta-analysis findings. Indian J. Cancer 54, 63-67 (2017).

7. Xiao, Y. et al. The impact of metformin use on survival in prostate cancer: a systematic review and meta-analysis. Oncotarget 8, 100449-100458 (2017).

8. Xie, W. et al. Metformin use and survival outcomes in endometrial cancer: a systematic review and meta-analysis. Oncotarget 8, 73079-73086 (2017).

9. Parikh, A. B., Kozuch, P., Rohs, N., Becker, D. J. \& Levy, B. P. Metformin as a repurposed therapy in advanced non-small cell lung cancer (NSCLC): results of a phase II trial. Investig. New Drugs 35, 813-819 (2017).

10. Song, C. W. et al. Metformin kills and radiosensitizes cancer cells and preferentially kills cancer stem cells. Sci. Rep. 2, 362 (2012).

11. Li, W., Saud, S. M., Young, M. R., Chen, G. \& Hua, B. Targeting AMPK for cancer prevention and treatment. Oncotarget 6, 7365-7378 (2015).

12. Vincent, E. E. et al. Differential effects of AMPK agonists on cell growth and metabolism. Oncogene 34, 3627-3639 (2014).

13. Foretz, M., Guigas, B., Bertrand, L., Pollak, M. \& Viollet, B. Metformin: from mechanisms of action to therapies. Cell Metab. 20, 953-966 (2014).

14. Madiraju, A. K. et al. Metformin suppresses gluconeogenesis by inhibiting mitochondrial glycerophosphate dehydrogenase. Nature 510, 542-546 (2014).

15. Janzer, A. et al. Metformin and phenformin deplete tricarboxylic acid cycle and glycolytic intermediates during cell transformation and NTPs in cancer stem cells. Proc. Natl. Acad. Sci. USA 111, 10574-10579 (2014).

16. Agarwal, N. R., Maurya, N., Pawar, J. S. \& Ghosh, I. A combined approach against tumorigenesis using glucose deprivation and mitochondrial complex 1 inhibition by rotenone. Cell Biol. Int. 40, 821-831 (2016).

17. Schockel, L. et al. Targeting mitochondrial complex I using BAY 87-2243 reduces melanoma tumor growth. Cancer Metab. 3, 11 (2015).

18. Morikawa, N., Nakagawa-Hattori, Y. \& Mizuno, Y. Effect of dopamine, dimethoxyphenylethylamine, papaverine, and related compounds on mitochondrial respiration and complex I activity. J. Neurochem. 66, 1174-1181 (1996).

19. Zhan, T., Rindtorff, N. \& Boutros, M. Wht signaling in cancer. Oncogene $\mathbf{3 6}$, 1461-1473 (2017).

20. Novellasdemunt, L., Antas, P. \& Li, V. S. W. Targeting Wnt signaling in colorectal cancer. a review in the theme: cell signaling: proteins, pathways and mechanisms. Am. J. Physiol. Cell Physiol. 309, C511-C521 (2015).

21. Song, G. D., Sun, Y., Shen, H. \& Li, W. SOX4 overexpression is a novel biomarker of malignant status and poor prognosis in breast cancer patients. Tumour Biol. J. Int. Soc. Oncodev. Biol. Med. 36, 4167-4173 (2015).

22. Vervoort, S. J., Lourenco, A. R., van Boxtel, R. \& Coffer, P. J. SOX4 mediates TGFbeta-induced expression of mesenchymal markers during mammary cell epithelial to mesenchymal transition. PLOS ONE 8, e53238 (2013).

23. Lin, C. M. et al. Clinical and prognostic implications of transcription factor SOX4 in patients with colon cancer. PLOS ONE 8, e67128 (2013).

24. Zhou, Y. et al. Down-regulated SOX4 expression suppresses cell proliferation, metastasis and induces apoptosis in Xuanwei female lung cancer patients. J. Cell. Biochem. 116, 1007-1018 (2015).

25. Foronda, M. et al. Sox4 links tumor suppression to accelerated aging in mice by modulating stem cell activation. Cell Rep. 8, 487-500 (2014).

26. Li, L. \& Li, W. Epithelial-mesenchymal transition in human cancer: comprehensive reprogramming of metabolism, epigenetics, and differentiation. Pharmacol. Ther. 150, 33-46 (2015).
27. Kim, J. H. et al. Roles of Wnt target genes in the journey of cancer stem cells. Int. J. Mol. Sci. 18, 1604 (2017)

28. Nhieu, J. T. et al. Nuclear accumulation of mutated beta-catenin in hepatocellular carcinoma is associated with increased cell proliferation. Am. J. Pathol. 155, 703-710 (1999).

29. Maiti, S., Alam, R., Amos, C. I. \& Huff, V. Frequent association of beta-catenin and WT1 mutations in Wilms tumors. Cancer Res. 60, 6288-6292 (2000).

30. Palacios, J. \& Gamallo, C. Mutations in the beta-catenin gene (CTNNB1) in endometrioid ovarian carcinomas. Cancer Res. 58, 1344-1347 (1998).

31. Voeller, H. J., Truica, C. I. \& Gelmann, E. P. Beta-catenin mutations in human prostate cancer. Cancer Res. 58, 2520-2523 (1998).

32. Zurawel, R. H., Chiappa, S. A., Allen, C. \& Raffel, C. Sporadic medulloblastomas contain oncogenic beta-catenin mutations. Cancer Res. 58, 896-899 (1998).

33. Zaman, G. J. R. et al. TTK inhibitors as a targeted therapy for CTNNB1 (betacatenin) mutant cancers. Mol. Cancer Ther. 16, 2609-2617 (2017).

34. Garcia-Rostan, G. et al. Frequent mutation and nuclear localization of betacatenin in anaplastic thyroid carcinoma. Cancer Res. 59, 1811-1815 (1999).

35. Reya, T. \& Clevers, H. Wht signalling in stem cells and cancer. Nature 434, 843-850 (2005).

36. Tammela, T. et al. A Wnt-producing niche drives proliferative potential and progression in lung adenocarcinoma. Nature 545, 355-359 (2017).

37. Dietrich, L. et al. Cell permeable stapled peptide inhibitor of Wnt signaling that targets beta-catenin protein-protein interactions. Cell Chem. Biol. 24, 958-968. e5 (2017).

38. Warburg, O. On respiratory impairment in cancer cells. Science 124, 269-270 (1956).

39. Janda, C. Y. et al. Surrogate Wnt agonists that phenocopy canonical Wnt and beta-catenin signalling. Nature 545, 234-237 (2017).

40. Bottomly, D., Kyler, S. L., McWeeney, S. K. \& Yochum, G. S. Identification of $\{$ beta\}-catenin binding regions in colon cancer cells using ChIP-Seq. Nucl. Acids Res. 38, 5735-5745 (2010).

41. Olsen, A. K. et al. Regulation of APC and AXIN2 expression by intestinal tumor suppressor CDX2 in colon cancer cells. Carcinogenesis 34, 1361-1369 (2013).

42. He, L. et al. Metformin and insulin suppress hepatic gluconeogenesis through phosphorylation of CREB binding protein. Cell 137, 635-646 (2009).

43. Iyer, N. G., Ozdag, H. \& Caldas, C. p300/CBP and cancer. Oncogene 23, 4225-4231 (2004)

44. Quentin, T., Steinmetz, M., Poppe, A. \& Thoms, S. Metformin differentially activates ER stress signaling pathways without inducing apoptosis. Dis. Model Mech. 5, 259-269 (2012).

45. Horndasch, M. et al. The C/EBP homologous protein CHOP (GADD153) is an inhibitor of Wnt/TCF signals. Oncogene 25, 3397-3407 (2006).

46. Raab, M. S. et al. Targeting PKC: a novel role for beta-catenin in ER stress and apoptotic signaling. Blood 113, 1513-1521 (2009).

47. Yoo, J. Y. et al. Bortezomib-induced unfolded protein response increases oncolytic HSV-1 replication resulting in synergistic antitumor effects. Clin. Cancer Res. Off. J. Am. Assoc. Cancer Res. 20, 3787-3798 (2014).

48. Li, Y., Guo, Y., Tang, J., Jiang, J. \& Chen, Z. New insights into the roles of CHOPinduced apoptosis in ER stress. Acta Biochim. Et. Biophys. Sin. 46, 629-640 (2014).

49. Bikas, A. et al. Glucose-deprivation increases thyroid cancer cells sensitivity to metformin. Endocr. Relat. Cancer 22, 919-932 (2015).

50. Justus, C. R., Dong, L. \& Yang, L. V. Acidic tumor microenvironment and pHsensing G protein-coupled receptors. Front Physiol. 4, 354 (2013).

51. Miesenbock, G., De Angelis, D. A. \& Rothman, J. E. Visualizing secretion and synaptic transmission with $\mathrm{pH}$-sensitive green fluorescent proteins. Nature 394, 192-195 (1998).

52. Koltai, T. Cancer: fundamentals behind pH targeting and the double-edged approach. OncoTargets Ther. 9, 6343-6360 (2016).

53. White, K. A., Grillo-Hill, B. K. \& Barber, D. L. Cancer cell behaviors mediated by dysregulated pH dynamics at a glance. J. Cell Sci. 130, 663-669 (2017).

54. Corbet, C. \& Feron, O. Tumour acidosis: from the passenger to the driver's seat. Nat. Rev. Cancer 17, 577-593 (2017).

55. de Sousa e Melo, F. et al. A distinct role for Lgr5+stem cells in primary and metastatic colon cancer. Nature 543, 676-680 (2017).

56. Zhang, $X$. et al. Lgr5-positive cells in the lung and their clinical significance in patients with lung adenocarcinoma. Mol. Clin. Oncol. 5, 283-288 (2016).

57. Tiwari, N. et al. Sox4 is a master regulator of epithelial-mesenchymal transition by controlling Ezh2 expression and epigenetic reprogramming. Cancer Cell 23, 768-783 (2013). 
58. Kuwahara, M. et al. The transcription factor Sox4 is a downstream target of signaling by the cytokine TGF-beta and suppresses $T(H) 2$ differentiation. Nat. Immunol. 13, 778-786 (2012).

59. Hanson, D. J. et al. Effective impairment of myeloma cells and their progenitors by blockade of monocarboxylate transportation. Oncotarget $\mathbf{6}$, 33568-33586 (2015).

60. Matsuzaki, S. \& Humphries, K. M. Selective inhibition of deactivated mitochondrial complex I by biguanides. Biochemistry 54, 2011-2021 (2015).

61. Zhang, Y. \& Ye, J. Mitochondrial inhibitor as a new class of insulin sensitizer. Acta Pharm. Sin. B 2, 341-349 (2012).

62. Acebron, S. P., Karaulanov, E., Berger, B. S., Huang, Y. L. \& Niehrs, C. Mitotic wnt signaling promotes protein stabilization and regulates cell size. Mol. Cell $\mathbf{5 4}$ 663-674 (2014)

63. Oyadomari, S. \& Mori, M. Roles of CHOP/GADD153 in endoplasmic reticulum stress. Cell Death Differ. 11, 381-389 (2004).

64. Shi, P. et al. Metformin suppresses triple-negative breast cancer stem cells by targeting KLF5 for degradation. Cell Discov. 3, 17010 (2017).

65. Weinberg, S. E. \& Chandel, N. S. Targeting mitochondria metabolism for cancer therapy. Nat. Chem. Biol. 11, 9-15 (2015).

66. Ippolito, J. E. et al. Extracellular pH modulates neuroendocrine prostate cancer cell metabolism and susceptibility to the mitochondrial inhibitor niclosamide. PloS ONE 11, e0159675 (2016).

67. Xie, J. et al. Beyond Warburg effect--dual metabolic nature of cancer cells. Sci. Rep. 4, 4927 (2014).

68. Chen, C. M., Wu, C. T., Chiang, C. K., Liao, B. W. \& Liu, S. H. C/EBP homologous protein (CHOP) deficiency aggravates hippocampal cell apoptosis and impairs memory performance. PLOS ONE 7, e40801 (2012).

69. $\mathrm{Xu}, \mathrm{H}$. et al. Metformin use is associated with better survival of breast cancer patients with diabetes: a meta-analysis. Oncologist 20, 1236-1244 (2015).

70. Henri, J., Burel, C., Sanders, P. \& Laurentie, M. Bioavailability, distribution and depletion of monensin in chickens. J. Vet. Pharmacol. Ther. 32, 451-456 (2009).

71. Naujokat, C. \& Steinhart, R. Salinomycin as a drug for targeting human cancer stem cells. J. Biomed. Biotechnol. 2012, 950658 (2012).

72. Gupta, P. B. et al. Identification of selective inhibitors of cancer stem cells by high-throughput screening. Cell 138, 645-659 (2009).

73. Bugde, P. et al. The therapeutic potential of targeting $A B C$ transporters to combat multi-drug resistance. Expert Opin. Ther. Targets 21, 511-530 (2017).

74. Vesel, M. et al. ABCB1 and ABCG2 drug transporters are differentially expressed in non-small cell lung cancers (NSCLC) and expression is modified by cisplatin treatment via altered Wnt signaling. Respir. Res. 18, 52 (2017).

75. Cruciat, C. M. et al. Requirement of prorenin receptor and vacuolar H+-ATPase-mediated acidification for Wnt signaling. Science 327, 459-463 (2010).

76. Holmen, S. L., Salic, A., Zylstra, C. R., Kirschner, M. W. \& Williams, B. O. A novel set of Wnt-Frizzled fusion proteins identifies receptor components that activate beta -catenin-dependent signaling. J. Biol. Chem. 277, 34727-34735 (2002).
77. van der Sanden, M. H., Meems, H., Houweling, M., Helms, J. B. \& Vaandrager, A B. Induction of CCAAT/enhancer-binding protein (C/EBP)-homologous protein/growth arrest and DNA damage-inducible protein 153 expression during inhibition of phosphatidylcholine synthesis is mediated via activation of a C/EBP-activating transcription factor-responsive element. J. Biol. Chem. 279, 52007-52015 (2004)

78. Pfeifer, A. C., Kaschek, D., Bachmann, J., Klingmuller, U. \& Timmer, J. Modelbased extension of high-throughput to high-content data. BMC Syst. Biol. 4, 106 (2010).

79. Swift, S., Lorens, J., Achacoso, P. \& Nolan, G. P. Rapid production of retroviruses for efficient gene delivery to mammalian cells using 293T cell-based systems, in Current Protocols in Immunology (John Wiley \& Sons, Inc., 2001).

80. Ketteler, R., Glaser, S., Sandra, O., Martens, U. M. \& Klingmuller, U. Enhanced transgene expression in primitive hematopoietic progenitor cells and embryonic stem cells efficiently transduced by optimized retroviral hybrid vectors. Gene Ther. 9, 477-487 (2002).

81. Rosdi, M. N. M., Daud, N., Zulkifli, R. Yaakob, H. Annona muricata Linn leaves extract cytotoxicity effect on Capan-1 cells. Journal of Appl. Pharm. Sci. 5, 45-48 (2015).

82. Burgstaller, G., Oehrle, B., Koch, I., Lindner, M. \& Eickelberg, O. Multiplex profiling of cellular invasion in 3D cell culture models. PloS ONE 8, e63121 (2013).

83. Llopis, J., McCaffery, J. M., Miyawaki, A., Farquhar, M. G. \& Tsien, R. Y. Measurement of cytosolic, mitochondrial, and Golgi pH in single living cells with green fluorescent proteins. Proc. Natl. Acad. Sci. USA 95, 6803-6808 (1998).

84. Orij, R., Postmus, J., Ter Beek, A., Brul, S. \& Smits, G. J. In vivo measurement of cytosolic and mitochondrial $\mathrm{pH}$ using a $\mathrm{pH}$-sensitive GFP derivative in Saccharomyces cerevisiae reveals a relation between intracellular $\mathrm{pH}$ and growth. Microbiology 155, 268-278 (2009).

85. DeYoung, M. B., MacConell, L., Sarin, V., Trautmann, M. \& Herbert, P. Encapsulation of exenatide in poly-(D,L-lactide-co-glycolide) microspheres produced an investigational long-acting once-weekly formulation for type 2 diabetes. Diabetes Technol. Ther. 13, 1145-1154 (2011).

86. Ramazani, F. et al. Strategies for encapsulation of small hydrophilic and amphiphilic drugs in PLGA microspheres: state-of-the-art and challenges. Int. J. Pharm. 499, 358-367 (2016).

87. Glinka, A., Wu, W., Onichtchouk, D., Blumenstock, C. \& Niehrs, C. Head induction by simultaneous repression of Bmp and Wnt signalling in Xenopus. Nature 389, 517-519 (1997)

88. Lefevre, P., Melnik, S., Wilson, N., Riggs, A. D. \& Bonifer, C. Developmentally regulated recruitment of transcription factors and chromatin modification activities to chicken lysozyme cis-regulatory elements in vivo. Mol. Cell. Biol. 23 4386-4400 (2003).

89. Beasley, M. B., Brambilla, E. \& Travis, W. D. The 2004 world health organization classification of lung tumors. Semin Roentgenol. 40, 90-97 (2005).

90. Abel, U., Berger, J. \& Wiebelt, H. CRITLEVEL: an exploratory procedure for the evaluation of quantitative prognostic factors. Methods Inf. Med. 23, 154-156 (1984). 